\title{
Papers
}

\section{Population based study of risk factors for underdiagnosis of asthma in adolescence: Odense schoolchild study}

Hans C Siersted, Jesper Boldsen, Henrik S Hansen, Gert Mostgaard, Niels Hyldebrandt

\begin{abstract}
Objective: To describe factors related to underdiagnosis of asthma in adolescence.

Design: Subgroup analysis in a population based cohort study.

Setting: Odense municipality, Denmark.

Subjects: 495 schoolchildren aged 12 to 15 years were selected from a cohort of 1369 children investigated 3 years earlier. Selection was done by randomisation $(n=292)$ and by a history indicating allergy or asthma-like symptoms in subject or family $(\mathrm{n}=203)$.
\end{abstract}

Main outcome measures: Undiagnosed asthma defined as coexistence of asthma-like symptoms and one or more obstructive airway abnormalities (low ratio of forced expiratory volume in 1 second to forced vital capacity, hyperresponsiveness to methacholine or exercise, or peak flow hypervariability) in the absence of physician diagnosed asthma. Risk factors (odds ratios) for underdiagnosis.

Results: Undiagnosed asthma comprised about one third of all asthma identified. Underdiagnosis was independently associated with low physical activity, high body mass, serious family problems, passive smoking, and the absence of rhinitis. Girls were overrepresented among undiagnosed patients with asthma (69\%) and underrepresented among diagnosed patients (33\%). Among the risk factors identified, low physical activity and problems in the family were independently associated with female sex. The major symptom among those undiagnosed was cough $(58 \%)$, whereas wheezing $(35 \%)$ or breathing trouble $(50 \%)$ was reported less frequently than among those diagnosed. Less than one third of those undiagnosed had reported their symptoms to a doctor.

Conclusions: Asthma, as defined by combined symptoms and test criteria, was seriously underdiagnosed among adolescents. Underdiagnosis was most prevalent among girls and was associated with a low tendency to report symptoms and with several independent risk factors that may help identification of previously undiagnosed asthmatic patients.

\begin{abstract}
Introduction
Epidemiological surveys have shown asthma-like symptoms to be far more prevalent than physician diagnosed asthma, ${ }^{1}$ and underdiagnosis of asthma has repeatedly been suspected during the past two decades, especially in children and young adults. ${ }^{23}$ Screening studies that used a combination of symptoms and objective indicators of asthma have confirmed this view. ${ }^{4-6}$ In the present cohort children who reported asthma-like symptoms but not asthma at age 10 had impaired lung function. ${ }^{7}$

Some risk factors for the underdiagnosis of asthma have recently been proposed, including female sex, ${ }^{6} 8$ low socioeconomic status, ${ }^{9}$ or belonging to an ethnic minority ${ }^{10}$ whereas the diagnostic process seems to be facilitated if previous episodes of acute bronchitis or a family history of asthma are reported. ${ }^{6}$

This population based study examined a broad selection of potential risk factors for underdiagnosis of asthma among adolescents with coexisting asthma-like symptoms and obstructive airway abnormalities.
\end{abstract}

\section{Subjects and methods}

The Odense schoolchild study is a prospective multidisciplinary epidemiological study in a community based cohort of 1369 schoolchildren first investigated during their third school year in 1985-6. ${ }^{11}$ The present analysis is based on data from 495 children aged 12 to 15 years and of Danish origin recruited from the original cohort for an extensive asthma and allergy screening programme. Subjects were selected either at random $(n=292)$ or on the basis of a history indicating asthma, allergy, or related symptoms or a family history of asthma or allergic rhinitis $(n=203){ }^{12}$ Subjects completed a comprehensive questionnaire and monitored their peak expiratory flow twice daily for 2 weeks. Laboratory examinations included anthropometric measurements, puberty staging, spirometry, treadmill exercise testing, and provocation with inhaled methacholine. Subjects were asked to stop taking bronchodilators (but not inhaled steroids) before testing. Informed consent was obtained from all children and parents or guardians before participation. The study was approved by the local research ethics committee, the local school board, and the Danish Data Surveillance Authority.

\author{
Section of \\ Respiratory \\ Diseases, \\ Department of \\ Medicine C, Odense \\ University Hospital, \\ DK-5000 Odense C, \\ Denmark \\ Hans C Siersted, \\ senior registrar \\ Gert Mostgaard, \\ registrar \\ Department of \\ Cardiology, Odense \\ University Hospital \\ Henrik S Hansen, \\ senior registrar \\ Centre for Health \\ and Social Policy, \\ Odense University, \\ DK-5230 Odense M \\ Jesper Boldsen, \\ senior lecturer \\ Private Specialist \\ Clinic, Nørregade \\ 16, DK-5000 \\ Odense C \\ Niels Hyldebrandt, \\ specialist in allergy \\ and internal medicine \\ Correspondence to: \\ Dr Siersted \\ hc.siersted@ \\ winsloew.ou.dk
}

BMJ 1998;316:651-7 
For the present analysis, currently symptomatic subjects were grouped according to the presence or absence of physician diagnosed asthma and positive test results. The variables analysed are listed in the box. Current asthma-like symptoms (ongoing or within the previous year) were identified by questionnaire as previously reported. ${ }^{12}$ Symptoms accepted included non-infectious cough, wheezing, and trouble breathing. Physician diagnosed asthma was identified by an affirmative answer to the question, "Is it your doctor's opinion, that you have asthma?" or the use of prescribed asthma medication, or both. Subjects with no previous diagnosis of asthma but asthma-like symptoms and at least one positive test result (hypervariability in peak expiratory flow, hyperresponsiveness to exercise or inhaled methacholine, or low ratio of forced expiratory volume in 1 second $\left(\mathrm{FEV}_{1}\right)$ to forced vital capacity (FVC)) were labelled as having undiagnosed asthma.

Details of test procedures have been reported previously. ${ }^{12}$ The body mass index (weight $(\mathrm{kg}) /$ (height $\left.(\mathrm{m})^{2}\right)$ ) was also calculated. Puberty staging was done according to Tanner and Whitehouse ${ }^{13}$ and corrected for age by sex. Forced expiratory volumes were measured according to European recommendations. ${ }^{14}$ For the 6 minute treadmill provocation test results were expressed as the lowest $\mathrm{FEV}_{1}$ obtained during the first 10 minutes after exercise in percentage of the best value before exercise. Bronchoprovocation with methacholine was performed according to Yan et $\mathrm{al}^{15}$ and expressed as the methacholine dose response slope. ${ }^{16}$ It was ensured that all subjects regained their baseline $\mathrm{FEV}_{1}$ (within 10\%) either spontaneously or aided by inhaled terbutaline (Bricanyl Turbohaler). Peak expiratory flow was recorded twice daily for 14 consecutive days with a Mini-Wright adult type peak flow meter. Variability in peak expiratory flow was expressed as the average of the two lowest values as a percentage of the period mean, after the first three recording days were discarded (the two lowest $\%$ mean index). ${ }^{17}$ Test results were considered abnormal if they were beyond the value delimiting the $5 \%$ "most asthmatic" part of the test distribution in 150 asymptomatic, non-smoking, and non-asthmatic reference subjects from the randomly selected part of the present cohort. The association of a range of medical, environmental, social, school, and activity related factors (see box) with undiagnosed versus diagnosed asthma and with asthma versus asthma-like symptoms only was assessed by logistic regression with SPSs. ${ }^{18}$

Variables that seemed to be differently distributed $(\mathrm{P}<0.15)$ between the groups compared were included in the logistic regression analysis by using backward selection (final removal criterion $\mathrm{P}>0.05$ ). Questionnaire information and test results directly related to grouping criteria were not included in the regression models but were analysed separately. The Medstat program (Astra Denmark, Copenhagen) was used to calculate $95 \%$ confidence intervals on proportions. Proportions were compared with $\chi^{2}$ statistics with Yates's correction.

\section{Results}

Among 495 subjects investigated, 128 had current asthma-like symptoms. Of these, 15 (12\%) were excluded from analysis because of missing data for

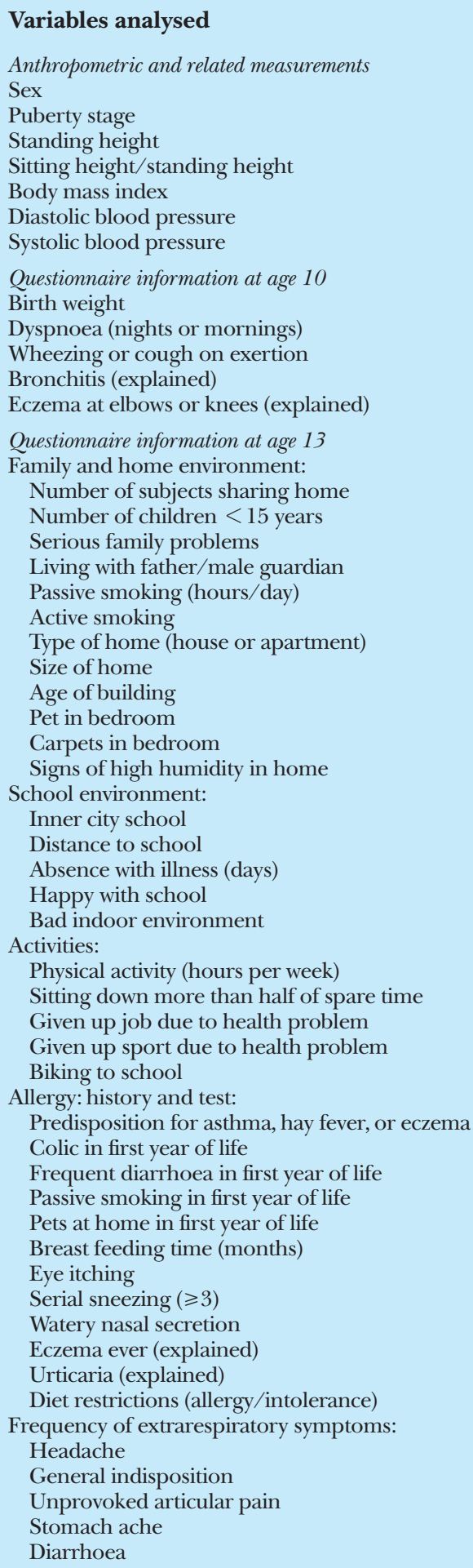

Physical activity (hours per week)

Sitting down more than half of spare time

Given up job due to health problem

Given up sport due to health problem

Biking to school

Allergy: history and test:

Predisposition for asthma, hay fever, or eczema

Colic in first year of life

Frequent diarrhoea in first year of life

Passive smoking in first year of life

Pets at home in first year of life

Breast feeding time (months)

Eye itching

Serial sneezing $(\geqslant 3)$

Watery nasal secretion

Eczema ever (explained)

Urticaria (explained)

Diet restrictions (allergy/intolerance)

Frequency of extrarespiratory symptoms:

Headache

General indisposition

Unprovoked articular pain

Stomach ache

Diarrhoea

group allocation. Forty five had physician diagnosed asthma, and 26 were considered as having undiagnosed asthma. The 42 remaining subjects had "symptoms only" (negative test results and not diagnosed with asthma). Despite the "normalising" effect of treatment with inhaled steroids on test results, ${ }^{12}$ the sensitivity of the test battery for symptomatic physician diagnosed asthma was high $(87 \%)$. The proportion of undiagnosed asthmatic sub- 
Table 1 Unadjusted associations of selected risk factors with undiagnosed asthma as opposed to asthma diagnosed by doctor

\begin{tabular}{|c|c|c|c|}
\hline Risk factor and categories & $\begin{array}{l}\text { Mean* or } \\
\text { proportion in } \\
\text { subjects with } \\
\text { asthma }\end{array}$ & $\begin{array}{l}\text { Odds } \\
\text { ratio }\end{array}$ & $\begin{array}{c}P \\
\text { value }\end{array}$ \\
\hline Sex (female $v$ male) & $33 / 71$ & 4.50 & 0.005 \\
\hline Body mass index† (per $\mathrm{kg} / \mathrm{m}^{2}$ ) & $19.9^{*}$ & 1.24 & 0.03 \\
\hline Systolic blood pressure (per mm Hg) & $116^{\star}$ & 1.04 & 0.07 \\
\hline $\begin{array}{l}\text { Symptoms on exercise at } 10 \text { years } \\
\text { (any } v \text { none) }\end{array}$ & $22 / 61$ & 0.12 & 0.008 \\
\hline Problems in family $†$ (severe $v$ trivial) & $6 / 70$ & 3.82 & 0.14 \\
\hline Living with father (yes $v$ no) & $56 / 70$ & 0.36 & 0.09 \\
\hline Passive smoking $\dagger$ (per hours/day) & $2.3^{*}$ & 1.46 & 0.005 \\
\hline Type of home (apartment $v$ house) & $11 / 70$ & 3.68 & 0.06 \\
\hline Pet in bedroom (yes $v$ no) & $30 / 71$ & 2.11 & 0.14 \\
\hline Carpets in bedroom (yes $v$ no) & $46 / 71$ & 7.33 & 0.004 \\
\hline Physical activity† (per hours/week) & $9.0^{*}$ & 0.86 & 0.004 \\
\hline $\begin{array}{l}\text { Spare time spent sitting (more } v \text { less } \\
\text { than half) }\end{array}$ & $18 / 71$ & 5.57 & 0.004 \\
\hline Given up sport (yes $v$ no) & $21 / 64$ & 0.39 & 0.12 \\
\hline Biking to school (yes $v$ no) & $53 / 69$ & 12.4 & 0.02 \\
\hline Diarrhoea before age 1 (frequent $v$ none) & $12 / 69$ & 0.12 & 0.05 \\
\hline Itching eyes (yes $v$ no) & $39 / 70$ & 0.25 & 0.008 \\
\hline Serial sneezing $\dagger$ (yes $v$ no) & $33 / 70$ & 0.14 & 0.0007 \\
\hline Watery nasal secretion (yes $v$ no) & $26 / 70$ & 0.12 & 0.002 \\
\hline Diet restrictions (yes $v$ no) & $26 / 70$ & 0.36 & 0.07 \\
\hline Headache (monthly) (yes $v$ no) & $24 / 71$ & 2.36 & 0.10 \\
\hline Stomach ache (monthly) (yes $v$ no) & $21 / 71$ & 2.57 & 0.08 \\
\hline
\end{tabular}

${ }^{*} \mathrm{~N}=62$ for passive smoking, $\geqslant 69$ for other continuous variables. †Included in final model (see table 2).

jects among all asthmatic subjects (36.6\%) did not differ significantly between subjects selected randomly or by history. The prevalence of any positive test result among 256 non-asthmatic subjects in the random group was $16.0 \%$ (not significantly different from the expected value $1-(0.95)^{4}=18.5 \%$ for four independent tests), and the symptom prevalence was $12.1 \%$. Thus, about eight subjects $(16 \%$ of $12 \%(1.9 \%)$ of 435 subjects with no previous diagnosis of asthma) may have been misclassified as having asthma by chance. After correction for this the proportion of asthmatic patients not previously diagnosed was $29 \%$ $(18 /(18+45))$.

\section{Undiagnosed versus diagnosed asthma}

Individual regression data for the 21 variables selected for logistic regression are shown in table 1. Adjusted odds ratios for independently contributing risk factors are given in table 2. Undiagnosed asthma was independently associated with self reported problems in the family ("we have very stressful problems in our family" (highest of three levels)), daily exposure to environmental tobacco smoke ("for how many hours a day are you usually exposed to indoor tobacco smoking"), low physical activity ("state average number of hours a week spent with physical activities"), high body mass index, and the absence of serial sneezing ("attacks of more than three consecutive sneezes")). No significant interactions between these factors were found.

Among those with diagnosed asthma only 33\% (95\% confidence interval $20 \%$ to $49 \%$ ) were girls compared with $69 \% \quad(48 \%$ to $86 \%)$ among those undiagnosed $(\mathrm{P}=0.007)$. The sex distribution was about neutral in the "symptoms only" group (52\%
(36\% to $68 \%)$ girls) and in the reference group (45\% (37\% to 54\%) girls). A negative association was found between female sex and physical activity (odds ratio 0.91 (0.84 to 1.00$)$ per hours/week, $\chi^{2}=4.12, \mathrm{df}=1$, $\mathrm{P}=0.04, \mathrm{n}=59$ ), whereas female sex and problems in the family were positively associated (14.8 (1.0 to 220), $\chi^{2}=3.97, \mathrm{df}=1, \mathrm{P}=0.05, \mathrm{n}=59$ ).

Cough was equally prevalent among diagnosed $(58 \%)$ and undiagnosed subjects $(58 \%)$, but the latter group reported less breathing trouble $(50 \%$ v 100\%, $\mathrm{P}<0.001)$ and wheezing $(35 \%$ v $96 \%, \mathrm{P}<0.001)$. Among undiagnosed subjects only $31 \%$ had reported any asthma-like symptom to a doctor. Subjects with diagnosed asthma had a significantly higher response to inhaled methacholine than did undiagnosed subjects with asthma (median methacholine dose response slope $12.0 v 4.8 \mu \mathrm{mol} / \mathrm{l}, \mathrm{P}=0.02$ ), whereas the results of baseline spirometry, exercise provocation, and peak flow monitoring did not differ between groups. No significant differences in test results were found between those subjects without asthma who had symptoms but negative test results and the reference group.

\section{Undiagnosed asthma versus symptoms only}

Among symptomatic subjects not previously diagnosed with asthma, independent risk factors (see box) for having undiagnosed asthma as opposed to asthmalike "symptoms only" were bronchitis at age 10 (odds ratio 7.35 ( 1.52 to 35.4 ), $\chi^{2}=6.2, \mathrm{df}=1, \mathrm{P}=0.01$ ), signs of humidity in home $\left(0.28(0.08\right.$ to 1.00$), \chi^{2}=3.81$, $\mathrm{df}=1, \mathrm{P}=0.05)$, and physical activity $(0.89(0.79$ to $\left.1.00), \chi^{2}=3.80, \mathrm{df}=1, \mathrm{P}=0.05\right)$. The odds ratios stated were adjusted for all contributing variables $(n=66$, two missing). No significant interactions were found between the variables contributing to model.

\section{Discussion}

Few studies have investigated the characteristics of previously undiagnosed asthmatic patients, probably in part because of the lack of an accepted definition of this condition and the need for objective measurements to confirm the diagnosis to avoid overestimation. $^{19}$ For epidemiology a pragmatic definition of asthma as the coexistence of recent wheeze and methacholine hyperresponsiveness has been proposed. ${ }^{20}$ Cough, however, may be the sole expression of asthma, ${ }^{21}$ and various tests of airway responsiveness may identify different types of abnormalities of the airways. $^{12}$ Therefore, we extended our definition of asthma to comprise non-infectious cough or any breathing trouble, or both, in combination with any test result confirming abnormal variations in airway calibre

Table 2 Associations of independent risk factors with undiagnosed asthma as opposed to asthma diagnosed by doctor

\begin{tabular}{lcccc} 
Risk factor and categories & $\begin{array}{c}\text { No of } \\
\text { subjects }\end{array}$ & $\begin{array}{c}\text { 0dds ratio } \\
(\mathbf{9 5 \%} \text { Cl) }\end{array}$ & $\begin{array}{c}\chi^{\mathbf{2}} \\
(\mathbf{d f}=\mathbf{1})\end{array}$ & $\begin{array}{c}\mathbf{P} \\
\text { value }\end{array}$ \\
\hline Body mass index $\left(\right.$ per $\left.\mathrm{kg} / \mathrm{m}^{2}\right)$ & 59 & $3.01(1.16$ to 7.83$)$ & 5.12 & 0.02 \\
\hline Problems in family (serious $v$ trivial) & 59 & $846(2.22$ to $\infty)$ & 4.94 & 0.03 \\
\hline Passive smoking (per hours/day) & 59 & $2.39(1.16$ to 4.92$)$ & 5.59 & 0.02 \\
\hline Physical activity (per hours/week) & 59 & $0.60(0.41$ to 0.87$)$ & 7.24 & 0.01 \\
\hline Serial sneezing (any $v$ none) & 59 & $0.005(0.00$ to 0.34$)$ & 5.99 & 0.01 \\
\hline
\end{tabular}

${ }^{*}$ Adjusted for all factors included in model. 
- One third of young people with asthma are not diagnosed; most are girls

- Undiagnosed asthma is associated with low physical activity, high body mass index, serious family problems, passive smoking, and the absence of symptoms of rhinitis

- Cough is the most common symptom among those with undiagnosed asthma

- Two thirds of those with undiagnosed asthma do not report their symptoms to a doctor, suggesting a need for targeted asthma campaigns likely to be strongly advised against and thus probably reduced when a child is diagnosed with asthma.

In accordance with previous reports, ${ }^{6}$ symptoms were rarely reported to a physician by undiagnosed subjects with asthma, who thereby effectively avoided getting diagnosed and properly treated. Cough seemed to be particularly overlooked as an expression of asthma. Even though the more severely affected patients with asthma (in terms of airway responsiveness and symptoms) were also the most likely to get diagnosed, several moderately to severely affected subjects were first identified as a result of the present study.

The role of atopy as a risk factor for asthma has been established by population based studies with physician independent markers of asthma such as lung function impairment, bronchial responsiveness to methacholine, or typical asthma symptoms. ${ }^{23-25}$ We speculate, however, that the traditional emphasis on two associated risk factors ${ }^{26}$ for asthma-namely, atopy and male sex-may have led to the underrecognition of non-atopic girls with asthma suggested by our data. It seems likely that allergy affecting nose or eyes facilitates a diagnosis of asthma, both by promoting contact with a doctor and by increasing the doctor's awareness towards this diagnosis.

\section{Undiagnosed versus diagnosed asthma}

Independent risk factors for undiagnosed as opposed to previously diagnosed asthma were serious family problems, low physical activity, high body mass index, high exposure to environmental tobacco smoke, and no history of serial sneezing, a characteristic symptom of allergic rhinitis. The first two of these risk factors were significantly associated with female sex, which, in accordance with previous reports, ${ }^{68}$ comprised two thirds of the undiagnosed but only one third of the diagnosed patients with asthma.

The logistic regression analysis was based on a relatively large number of potential risk factors $(n=51)$ compared with the number of asthmatic subjects identified $(n=71)$. Thus, mass significance could not be excluded. The relevance of the five independent risk factors, however, was supported by the presence of several associated factors competing for entry in the final model (see table 1).

\section{Why is asthma overlooked?}

The presence of one or more of the five independent risk factors could in several ways lead to misinterpretation or neglect of asthma-like symptoms by patients, parents, or medical professionals. A low level of physical activity is relatively unlikely to provoke symptoms of asthma induced by exercise and may serve as a means of self "treatment" in childhood asthma. Furthermore, low activity promotes weight gain (high body mass index) which in turn may lead to misinterpretation of asthma symptoms as due to lack of physical fitness. Social status, previously associated with underdiagnosis of asthma, ${ }^{9}$ was not directly measured but may be related to parents' smoking habits as well as problems in the family. Family problems may reduce focus on a child's symptoms, and parents who smoke may be disinclined to get a doctor's advice regarding symptoms related to smoking in the family. Environmental tobacco smoke has previously been shown to be a risk factor for childhood wheeze ${ }^{22}$ and is

\section{Undiagnosed asthma versus symptoms only}

Undiagnosed patients with asthma also differed from those with symptoms but with no evidence of asthma. In this context, previously undiagnosed asthma at age 13 was positively associated with symptoms of bronchitis-that is, periodic cough for many days or weeks-at age 10, confirming earlier reports on misclassification of asthma as bronchitis ${ }^{4}$ and suggesting that the asthma had been unrecognised for several asthma and the level of physical activity suggests that exercise induced symptoms limit the activity level in undiagnosed subjects more than in subjects with respiratory symptoms unrelated to asthma. The independent association of indicators of high humidity in the home with non-asthmatic respiratory symptoms was unexpected but may be related to indoor microbial factors. ${ }^{27}$

\section{Summary}

Substantial underdiagnosis of asthma in the adolescent population was confirmed by combined subjective and objective criteria. Underdiagnosis was independently associated with low physical activity, high body mass, serious family problems, passive smoking, and the absence of rhinitis symptoms. Girls were overrepresented among subjects with undiagnosed asthma and equally underrepresented among those with diagnosed asthma, indicating sex bias in the diagnostic process. Most patients with undiagnosed asthma had not need for targeted asthma campaigns in the community.

We thank the participants, their parents, and the schools involved for their cooperation, and Ellen Møhl, Birgitte Pedersen, and Susanne Berntsen for skilful technical help.

Contributors: NH initiated the Odense schoolchild study together with HSH, who carried out the background study. HCS designed the protocol for the present follow up study together with NH and HSH. HCS carried out data collection and quality control in cooperation with the technicians acknowledged years. The negative association between undiagnosed reported their symptoms to a physician, suggesting a 
above, had the original idea for the present analysis, and wrote the manuscript. HCS also carried out the statistical analysis after thorough discussion with JB and GM. All coauthors made valuable comments to the manuscript and approved the final version. HCS is the guarantor for the study.

Funding: Danish Medical Research Council, Danish National Association against Lung Diseases, Danish Asthma and Allergy Association, the Højbjerg Foundation, and Odense University.

Conflict of interest: None.

1 Sears MR. Epidemiological trends in bronchial asthma. In: Kaliner MA Barnes PJ, Persson CGA, eds. Asthma: its pathology and treatment. New York: Marcel Dekker, 1991

2 Speight AN. Is childhood asthma being underdiagnosed and undertreated? $B M J$ 1978;29:331-2.

3 Nish WA, Schwietz LA. Underdiagnosis of asthma in young adults presenting for USAF basic training. Ann Allergy 1992;69:239-42.

4 Speight AN, Lee DA, Hey EN. Underdiagnosis and undertreatment of asthma in childhood. BMJ 1983;286:1253-6.

5 Cuijpers C, Wesseling GJ, Swaen GMH, Sturmans F, Wouters EFM. Asthma-related symptoms and lung function in primary school children. JAsthma 1994:31:301-12.

6 Kolnaar BGM, Beissel E, van den Bosch WJHM, Folgering $\mathrm{H}$, van den Hoogen HJM, van Weel C. Asthma in adolescents and young adults: screening outcome versus diagnosis in general practice. Fam Prac 1994;11:133-40

7 Mostgaard G, Siersted HC, Hansen HS, Hyldebrandt N, Oxhøj H. Reduced forced expiratory flow in schoolchildren with respiratory symptoms: the Odense schoolchild study. Resp Med 1997;91:443-8.

8 Kuhni CE, Sennhauser FH. The Yentl syndrome in childhood asthma: risk factors for undertreatment in Swiss children. Pediatr Pulmonol 1995;19:156-60

9 Baumann A, Young L, Peat JK, Hunt J, Larkin P. Asthma underrecognition and undertreatment in an Australian community. Aust NZ Med 1992;22:36-40.

10 Duran-Tauleria E, Rona RJ, Chinn S, Burney P. Influence of ethnic group on asthma treatment in children in 1990-1: national cross sectional study. BMJ 1996;313:148-52.

11 Hansen HS, Hyldebrandt N, Nielsen JR, Froberg K. Blood pressure distribution in a school-age population aged 8-10 years: the Odense schoolchild study.J Hypertens 1990;8:641-6

12 Siersted HC, Mostgaard G, Hyldebrandt N, Hansen HS, Boldsen J, Oxhøj $\mathrm{H}$. Interrelationships between diagnosed asthma, asthma-like symptoms, and abnormal airway behaviour in adolescence: the Odense schoolchild study. Thorax 1996;51:503-9.

13 Tanner JM, Whitehouse RH. Clinical longitudinal standards for height, weight, height velocity, weight velocity, and stages of puberty. Arch Dis Childhood 1976;51:170-9.

14 Quanjer $\mathrm{PhH}$, ed. Standardized lung function testing. Report of the working party on standardization of lung function tests, European Community for Coal and Steel. Bull Europ Physiopath Respir 1983;19 (supp 5): $1-95$

15 Yan K, Salome C, Woolcock AJ. Rapid method for measurement of bronchial responsiveness. Thorax 1983;38:760-5.

16 O'Connor G, Sparrow D, Taylor D, Segal M, Weiss S. Analysis of dose-response curves to methacholine. An approach suitable for population studies. Am Rev Respir Dis 1987;136:1412-7.

17 Siersted HC, Hansen HS, Hansen N-CG, Hyldebrandt N, Mostgaard G, Oxhøj H. Evaluation of peak expiratory flow variability in an adolescent population sample. The Odense schoolchild study. Am J Respir Crit Care Med 1994;149:598-603.

18 Norusis MJ. SPSS/PC+ advanced statistics version 4.0. Chicago: SPSS, 1990.

19 Joyce DP, Chapman KR, Kesten S. Prior diagnosis and treatment of patients with normal results of methacholine challenge and unexplained respiratory symptoms. Chest 1996;109:697-701.

20 Toelle BG, Peat JK, Salome CM, Mellis CM, Woolcock AJ. Toward a definition of asthma for epidemiology. Am Rev Respir Dis 1992;146:633-7.

21 Hannaway PJ, Hopper GD. Cough variant asthma in children. JAMA 1982;247:206-8.

22 Cunningham J, O'Connor GT, Dockery DW, Speizer FE. Environmental tobacco smoke, wheezing, and asthma in children in 24 communities. Am J Respir Crit Care Med 1996;153:218-24.

23 Peat JK, Britton WJ, Salome CM, Woolcock AJ. Bronchial hyperresponsiveness in two populations of Australian schoolchildren. II. Relative importance of associated factors. Clin Allergy 1987;17:283-90.

24 Clough JB, Williams JD, Holgate ST. Effect of atopy on the natural history of symptoms, peak expiratory flow, and bronchial responsiveness in 7 and 8-year-old children with cough and wheeze. Am Rev Respir Dis 1991;143:755-60

25 Sears MR, Burrows B, Herbison GP, Flannery EM, Holdaway MD. Atopy in childhood. III. Relationship with pulmonary function and airway responsiveness. Clin Exp Allergy 1993;23:957-63.

26 Sears MR, Burrows B, Flannery EM, Herbison GP, Holdaway MD. Atopy in childhood. I. Gender and allergen related risks for development of hay fever and asthma. Clin Exp Allergy 1993;23:941-8.

27 Husman T. Health effects of indoor-air microorganisms. Scand J Work Environ Health 1996;22:5-13.

(Accepted 2 October 1997)

\section{Commentary: Risk factors for underdiagnosis of asthma in adolescence}

\section{P John Rees}

The Odense schoolchild study of asthma symptoms has provided previous data on this same group of children. ${ }^{1}$ The results in adolescents with diagnosed asthma showed that different objective tests (spirometry, responsiveness to methacholine or exercise, variability in peak flow at home) may pick up different subsets of airway pathophysiology. In the current study they have shown that around a third of children who have asthma-like symptoms and one positive test result have not been given a diagnosis of asthma. They suggest that this may be a reason to go out and search for these cases in the community.

Firstly, we need to know whether this underdiagnosis of asthma matters. Possible reasons for such a search might be that these children have current problems such as persistent symptoms which could be relieved by appropriate treatment, have restricted activity because of respiratory symptoms on exercise, or are at risk of severe asthma attacks because of the absence of diagnosis and treatment. Alternatively, there might be longer term risks of more troublesome asthma symptoms in the future or the development of irreversible airway damage which could have been prevented by treatment.

Only $31 \%$ of the undiagnosed group had presented an asthma-like symptom to a doctor. In a few cases this might have been reticence related to an anxiety about the doctor's response to parental smoking. The association found between undiagnosed asthma and limited activity or a higher body mass index suggests that a healthier life style might have brought symptoms to light or that symptoms might have been related inappropriately to weight or lack of fitness.

Overall, the symptoms in the undiagnosed group were milder; breathlessness was less common than in the diagnosed group and methacholine responsiveness was lower. In some cases, however, the findings were less reassuring as "several moderately to severely affected subjects were first identified as a result of the present study." Some of these subjects in the undiagnosed group may have been poor perceivers of their asthma, ${ }^{2}$ a group of patients who need particular care and who may be particularly susceptible to future acute problems. ${ }^{3}$

These might be legitimate reasons to search for such cases or, at least, to be ready to suspect the diagnosis with few symptoms and the associations shown here. Any argument that the longer term clinical course of asthma might be favourably changed by early diagnosis and treatment of these cases with
United Medical and Dental Schools of Guy's and St Thomas's Hospitals, London SE1 9RT P John Rees, consultant physician 
mild symptoms is more difficult to sustain on the present evidence. There is a suggestion that persistent inflammation may cause remodelling of the airways, leaving them less able to reverse back to their full calibre. ${ }^{4}$ Early intervention with corticosteroids is known to control symptoms, reduce inflammation, ${ }^{5}$ and improve bronchial responsiveness. There are suggestions that such treatment might even prevent irreversible change, ${ }^{6}$ but the evidence is not strong enough to recommend this approach in all of the undiagnosed group with minimal symptoms.

So where does this leave us? It does not provide the evidence for screening in the community until we know that this is beneficial on quality of life or long term outlook. It does show that there are still people with asthma with significant problems who remain undiagnosed and untreated because they or their doctors fail to appreciate the importance of their symptoms. This paper shows some associated features such as physical inactivity, high body mass index, and lower socioeconomic class, which should raise suspicions that the diagnosis is being missed where symptoms are mild. An exercise test, peak flow at home, methacholine challenge, or a combination should be used to confirm the diagnosis. The advantage of the first two tests is that they can be performed easily by primary care physicians who see most of these children. A positive diagnosis or a high degree of suspicion with significant symptoms should prompt a trial of treatment.

1 Siersted HC, Mostgaard G, Hyldebrandt N, Hansen HS, Boldsen J, Oxhoj $\mathrm{H}$. Interrelationships between diagnosed asthma, asthma-like symptoms, and abnormal airway behaviour in adolescence: the Odense schoolchild study. Thorax 1996;51:503-9.

2 Rubinfeld AR, Pain MCF. Perception of asthma. Lancet 1976;i:882-4.

3 Kikochi Y, Okabe S, Tamura G, Hida W, Homma M, Shirato K, et al. Chemosensitivity and perception of dyspnea in patients with a history of near-fatal asthma. N Engl J Med 1994:330:1329-34.

4 Laitinen LA, Laitinen A, Altraja A, Virtanen l, Kampe M, Simonsson BG, et al. Bronchial biopsy findings in intermittent or "early" asthma. J All Clin Immunol 1996;98:35-6.

5 Trigg CJ, Manolitsas ND, Wang J, Calderon MA, McAulay A, Jordan SE, et al. Placebo controlled immunopathologic study of four months of inhaled corticosteroids in asthma. Am I Respir Crit Care Med 1994;150:17-22

6 Haahtela MJ, Jarvinen M, Kava T, Kiviranta K, Koskinen S, Lehtonen K, et al. Effects of reducing or discontinuing inhaled budesonide in patients with mild asthma. N Engl J Med 1994;331:700-5.

\title{
Commentary: Identifying the correct risks in diagnosis
}

\author{
Stephen J W Evans
}

London School of Hygiene and Tropical Medicine, London WC1 Stephen J W Evans, visiting professor of medical statistics
This is a study of young people selected in two ways: firstly, a simple random sample of 292 (21\%) children from 1369 in an epidemiological study, and, secondly, a $100 \%$ sample (203) of those with personal or family history of asthmatic-like symptoms. (The consequences for analysis of this method of sample selection have been ignored but probably hardly affect the conclusions.) These children were classified into three groups: firstly, those who described themselves as having physician diagnosed asthma; secondly, those with asthma-like symptoms and a positive test result but without a doctor's diagnosis-undiagnosed asthma; and, thirdly, those non-smokers with no symptoms or diagnosis of asthma-the reference group (smokers with no symptoms were excluded).

Logistic regression is a statistical technique that may be used to combine factors that discriminate between two groups. It requires a "gold standard" diagnostic test (which may be invasive or expensive or one for which the result can be obtained only retrospectively) and putative features to be used for discrimination to be measured on all those classified by the gold standard. Generally the groups studied are those with and without disease. Logistic regression can be used to estimate a probability, from the measured features, that a particular individual has the disease.

This study uses the technique to examine features that might be used in those children with asthma to discriminate between those who are diagnosed and those who are not diagnosed. Is this discrimination of value? It may be of marginal interest in theory but does not seem to help practitioners. When a doctor is faced with a patient, the problem is to discriminate between those who have and those who do not have asthma, so that he or she can give appropriate treatment. If they have already made a diagnosis then distinctions between those with and those without such a diagnosis are no longer of interest.

The fact that being a girl is a "risk factor" for being undiagnosed does not necessarily help unless it also distinguishes between having symptoms only and being undiagnosed. It does suggest that boys are more likely to be diagnosed, but there may be more girls in the non-asthmatic group as a whole. The tables and most of the text of the paper do not contribute to the useful distinction. The results for the discrimination between "symptoms only" and "undiagnosed asthma" are neither very significant (only bronchitis at age 10 is conventionally significant) nor are they the same set of variables for distinguishing between diagnosed and undiagnosed asthma. Physical activity shows a similar trend but is not very helpful in making the clinical decisions with which a doctor is faced in the clinic or general practice.

The message of this paper is that statistical techniques can serve to produce analyses which, while arithmetically correct, are irrelevant. It is an error of the third kind: "Finding the right answer to the wrong question."

\section{Correction}

Systematic overview of co-proxamol to assess analgesic effects of addition of dextropropoxyphene to paracetamol

An editorial error occurred in this paper by Li Wan Po and Zhang (13 December, pp 1565-71). In figure 2 the mean rate ratios $(95 \%$ confidence intervals) for moderate to excellent pain relief between treatments should have been given as numbers [not as percentages, as published]. 


\title{
Commentary: Improving the diagnostic rate in asthma: a community issue
}

Hans C Siersted

Our definition of asthma-the coexistence of asthmalike symptoms and obstructive airway abnormality-is widely accepted. The test battery and the diagnostic algorithm are routinely used in specialist clinics, and similar principles are applied by general practitioners. Thus we believe that asthma diagnosed in our community based study would also be diagnosed as such if the children visited an observant general practitioner. Our study shows, however, that in many patients asthma is not properly diagnosed.

Most importantly, most of these patients with undiagnosed asthma did not even report their symptoms to a doctor. Therefore we asked ourselves the question: can characteristics of these children with undiagnosed asthma be identified to help to increase awareness about the possibility of asthma in children with respiratory symptoms that are not obviously abnormal to parents, guardians, and school teachers? We believe that knowledge of the risk factors identified for not having asthma diagnosed could certainly promote the diagnostic decision process, especially at the community level (figure), leading new candidates for asthma evaluation to the doctor's waiting room. If then the doctor, considering also risk factors for underdiagnosis, agrees that a patient's symptoms could possibly be asthma, it is not the right time to wonder if more risk factors could help differentiate between asthma and "symptoms only." Instead, it is the time for tests such as peak flow monitoring

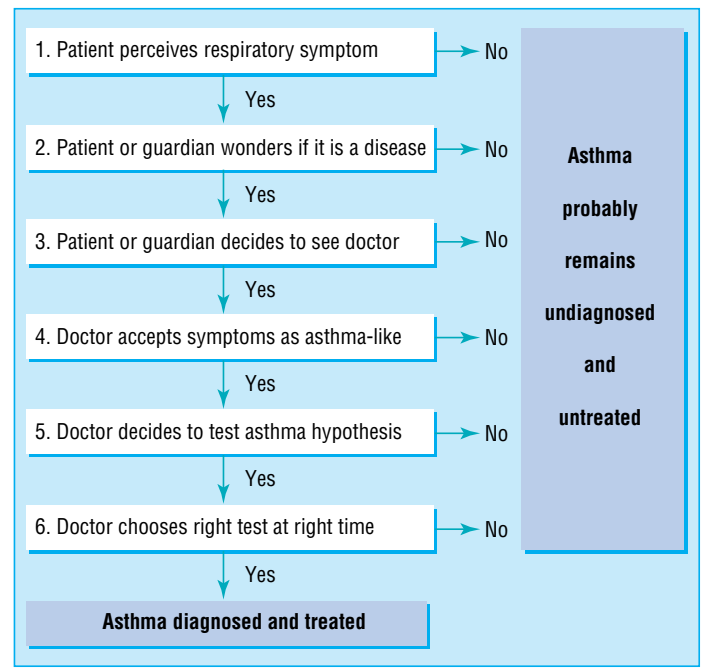

Stepwise path for diagnosing asthma in patients with respiratory symptoms

and (if these are negative) challenge with methacholine or exercise.

Thus, knowledge of pitfalls (risk factors for underdiagnosis)-for example, explaining cough alone as a natural response to passive smoking and exercise dyspnoea as simply the result of obesity - may be helpful at all stages of the diagnostic path towards the right answer to the asthma question.

\section{Numbers of deaths related to intrapartum asphyxia and timing of birth in all Wales perinatal survey, 1993-5}

\author{
Jane H Stewart, Joan Andrews, Patrick H T Cartlidge
}

\begin{abstract}
Objectives: To investigate the relation between the timing of birth and the occurrence of death related to an intrapartum event.

Design: Analysis of 107206 births to Welsh residents in 1993-5, including 608 cases of stillbirth and 407 of neonatal death identified in the all Wales perinatal survey, the cause of death classified with the clinicopathological system.

Subjects: 79 normally formed babies stillborn or who died in the neonatal period, birth weight $>1499 \mathrm{~g}$, for whom cause of death was related to an intrapartum event.

Main outcome measures: Relative risk of death due to an intrapartum event according to the hour, day, and month of birth.
\end{abstract}

Results: Mortality was higher in babies born between $900 \mathrm{pm}$ and $859 \mathrm{am}$ than in those born between 900 am and 859 pm; relative risk (95\% confidence interval) 2.18 (1.37 to 3.47). July and August births also had a higher death rate than births in other months; relative risk 1.99 (1.23 to 3.23). Weekend births had a higher death rate but it was not significant.

Conclusions: The excess of deaths at night and during months when annual leave is popular may indicate an overreliance on inexperienced staff at these times. Errors of judgment may also be related to physical and mental fatigue, demanding a more disciplined systematic approach at night. Mistakes may be ameliorated by increasing shiftwork, but shifts should be carefully designed to avoid undue disruption of circadian rhythms. In addition, greater supervision by senior staff may be required at night and during summer months.
Section of

Respiratory Diseases,

Department of

Medicine C, Odense

University Hospital,

DK-5000 Odense C,

Denmark

Hans C Siersted, senior registrar
Editorial by Spencer

Department of Child Health, University of Wales College of Medicine, Cardiff CF4 4XN Jane H Stewart, research midwife Joan Andrews, consultant obstetrician Patrick H T Cartlidge, senior lecturer in child health

Correspondence to: Dr Cartlidge cartlidge@cf.ac.uk

BMJ 1998;316:657-60 


\section{Introduction}

The sharp fall in perinatal mortality in the United Kingdom in recent decades has been ascribed both to an improvement in general health and to specific advances in perinatal care. ${ }^{1}$ Death due to intrapartum asphyxia of a mature and normally formed baby is now uncommon, but because labour is a time of maximum clinical supervision these deaths are widely considered to be the most preventable component of perinatal mortality. ${ }^{2}$ Indeed, in a low risk pregnancy the incidence of stillbirths or neonatal deaths due to intrapartum asphyxia is regarded as a sensitive measure of the quality of care around the time of labour and delivery. ${ }^{3-5}$

In 1992 the confidential inquiry into stillbirths and deaths in infancy was established in England, Wales, and Northern Ireland. ${ }^{6}$ This inquiry initially focused on deaths related to intrapartum events to delineate the components of perinatal care most frequently associated with a poor outcome. The fourth annual report of the inquiry concentrated on the results of 873 "intrapartum related deaths" that took place in 1994 and 1995 and showed that more than half the cases were linked to suboptimal care; the most common deficiencies were related to clinical management, with staff failing to recognise problems or failing to act appropriately once a problem was identified. ${ }^{7}$ These issues were linked with deficiencies in training and a lack of senior supervision around the time of delivery.

Maintaining a consistent level of readily available and experienced staff for the management of labour is sometimes difficult because the occurrence of a perinatal emergency is largely unpredictable. Problems may occur when training grade staff begin working in a specialty in which initially they have little experience. Also, staffing levels may fluctuate during holiday periods, when annual leave is most popular, and during unsociable hours (nights and weekends). ${ }^{8}$ In this study we investigated the relation between the hour, day, and month of delivery and the incidence of deaths related to an intrapartum event.

\section{Subjects and methods}

We identified 608 stillbirths and 407 neonatal deaths in 1993-5, using the all Wales perinatal survey, a population based surveillance of mortality between 20 completed weeks of gestation and 1 year of age. ${ }^{9}$ The births were to women usually resident in Wales, irrespective of the place of delivery. Information about each death was collected on the survey questionnaire that was normally completed by the team in whose unit the baby died. ${ }^{9}$ This included details about the mother (medical and obstetric history, current pregnancy, labour, and delivery) and baby (sex, birth weight, gestation, clinical management, and postmortem findings). This information was used by local staff to classify the cause of death by using the clinicopathological system $^{10} 11$ and verified for accuracy by the regional coordinating team. Completeness of ascertainment of stillbirths and neonatal deaths was validated by cross checking with data from the Office for National Statistics and the Child Health System Database. ${ }^{12}$

Data on surviving infants were obtained from the Child Health System Database, which collects infor- mation on Welsh residents from the birth notification record. ${ }^{12}$ There were 107206 registrable births during the period of investigation, maternity care being delivered in 16 consultant obstetric units and 11 general practitioner units within Wales and several hospitals in neighbouring English health authorities; home deliveries accounted for $1.8 \%$ of all births. The rate of caesarean section in Welsh maternity units in 1993-5 was $16.8 \%$, and the elective caesarean section rate was $6.7 \% .{ }^{9}$

The study relates to deaths in 1993-5 classified as being due to an intrapartum related event ${ }^{911}$ for babies with a birth weight $>1499 \mathrm{~g}$ who died during labour or within 28 completed days of life. The hour, day, and month of birth of these infants was compared with that of surviving infants. The effect of being born at night was analysed by comparing the death rate for births between 900 am and $859 \mathrm{pm}$ (day) with that between $900 \mathrm{pm}$ and 859 am (night). July and August were considered the peak months of annual leave so the death rate for births in these months was compared with that for the rest of the year. Senior house officers in Wales rotate to new posts in February and August; the effect of this was assessed by comparing the death rate for births in these months with that during the rest of the year.

Relative risks and 95\% confidence intervals were calculated to assess the effect of each factor on death rates. Multiple logistic regression was used to determine whether the different factors contributed independently to the rate of death.

\section{Results}

A total of 79 deaths $(0.74 / 1000$ total births) related to an intrapartum event were identified. Birth weight ranged between $1500 \mathrm{~g}$ and $4805 \mathrm{~g}$ (median $3050 \mathrm{~g}$ ) and gestational age between 29 and 43 weeks (median 39 weeks). Seventy cases were from singleton pregnancies and nine from twin pregnancies; in one set of twins both fetuses were stillborn. Twelve deaths (eight at night) were after an induction of labour, 38 (25 at night) at emergency caesarean section, and none at elective caesarean section. There were 33 deaths during labour, 42 early neonatal deaths, and four late neonatal deaths.

The intrapartum related death rate was higher in babies born at night. There were 27 deaths from 56892 births between 900 am and 859 pm (0.47/ 1000) compared with 52 deaths from 50314 births between $900 \mathrm{pm}$ and 859 am (1.04/1000), a relative risk of death of 2.18 (95\% confidence interval 1.37 to 3.47). If babies born during the daytime by elective caesarean section (rate 6.7\%) and therefore not exposed to labour are excluded from the analysis, the difference remains significant with a relative risk of death of 1.95 (1.22 to 3.10).

Births in July and August (annual leave effect) had a significantly higher rate of intrapartum related death $(1.25 / 1000$ births) compared with births in other months $(0.63 / 1000 /$ births $)$, with a relative risk of death of 1.99 (1.23 to 3.23) (table). The death rate for births in February and August (rotation effect) was also significantly higher (1.25/1000 births), with a relative risk of death of 1.97 (1.21 to 3.22). As August births feature in both the annual leave and rotation months, further analysis with multiple logistic regression was performed to establish whether the two effects were independent. When these factors were analysed 
Numbers of intrapartum related deaths and month of birth in all Wales perinatal survey, $1993-5$

\begin{tabular}{lcc} 
Month of birth & No of deaths & No of births \\
\hline January & 4 & 8858 \\
\hline February & 10 & 8305 \\
\hline March & 4 & 9139 \\
\hline April & 5 & 8894 \\
\hline May & 6 & 9398 \\
\hline June & 6 & 9118 \\
\hline July & 11 & 9092 \\
\hline August & 12 & 9237 \\
\hline September & 2 & 9200 \\
\hline October & 5 & 8788 \\
\hline November & 5 & 8484 \\
\hline December & 9 & 8693 \\
\hline Total & 79 & 107206
\end{tabular}

together the rotation effect was no longer significant $(\mathrm{P}=0.1088)$.

Using the same methodology we tested whether night, annual leave, and rotation effects all influenced the death rate when analysed together. We found that the annual leave and night effects were significant $(\mathrm{P}=0.0056$ and $\mathrm{P}=0.0011$, respectively) but that the rotation effect was not $(\mathrm{P}=0.1082)$.

There was a tendency for babies born towards the end of the week to have a higher rate of intrapartum related deaths. Monday and Tuesday births had the lowest relative risk of death of 0.78 (0.39 to 1.57$)$ and 0.71 (0.36 to 1.43), respectively, in contrast with 1.20 (0.68 to 2.21) and 1.48 (0.82 to 2.68) on Saturday and Sunday. These differences, however, were not significant.

\section{Discussion}

This population based study has highlighted a variation in the risk of death due to an intrapartum event according to the time of birth, with the most striking feature being the higher risk of death for babies born at night. In view of the recognised association of care around the time of delivery with outcome, this must raise concerns about variability in the quality of perinatal care.

The increased risk of being born at night could be explained if induced labours, which have a higher risk of intrapartum complications, are selectively more likely to result in a delivery at night. These data were not available for all births, but in one health district with $15 \%$ of deliveries and comparable induction rates, night time birth was less common after an induction of labour $(48 \%)$ than after a spontaneous labour (52\%) (J Bethel, personal communication). Induction of labour is therefore unlikely to be the explanation.

Specific information on staffing levels and the availability of experienced staff at the moment of birth was not available. Nevertheless, one of the more plausible explanations for intrapartum related deaths being associated with birth during the night is a reduced availability of skilled and experienced staff at this time. This view is supported by an audit by Meer et al, who reported that in the West Midlands most suboptimal obstetric practice occurs out of office hours. ${ }^{13}$ It is also consistent with a finding of the confidential inquiry into perioperative deaths that the risk of surgery conducted out of hours is higher because it tends to be performed by junior surgeons without supervision. ${ }^{14}$

\section{Hours of work}

Errors of judgment are more likely if staff are physically and mentally tired. ${ }^{15}$ Obstetrics differs from other medical specialties in the excess night time hours (9 pm to $9 \mathrm{am}$ ) worked by junior medical staff compared with staff in other disciplines. ${ }^{8}$ Night time tiredness should have been lessened by the recent widespread introduction of shiftwork among junior medical staff, but this pattern of work is unpopular, ${ }^{16}$ and continuity of patient care may be affected. Shiftwork can also be profoundly affected by circadian rhythms, resulting in fatigue during the last few hours of the night, especially if the person is on a new night shift. ${ }^{17}$ In comparison to staff who work only nights, those who rotate shifts report twice as many errors related to tiredness. ${ }^{17}$ The adverse effects of shifts on health and performance are most pronounced when rotations last fewer than 3 weeks, and circadian rhythms are further disrupted if the shift rotation is counterclockwise. ${ }^{15}$

\section{Effect of month of birth}

We have also found an increased risk of an intrapartum related death among babies born in July and August, when annual leave is popular. At these times junior medical staff may be less well supervised and perinatal services may rely more heavily on locum staff employed to cover annual leave. This effect is exacerbated if the staffing establishment has no built in allowances to cover staff absence. Indeed, research commissioned by the Department of Health into patterns of staffing in obstetrics found that during holiday periods one of the units surveyed was on occasion nearly crippled by staff shortages. ${ }^{8}$ Babies born in February and August, when senior house officers rotate to new posts, were not at a significantly increased risk. This may indicate that critical decisions are usually made by other members of staff, but nevertheless it is unfortunate that inexperienced medical staff rotate to new posts in August, when senior staff may be on annual leave.

\section{Conclusion}

Deaths related to an intrapartum event are more common among babies born at night and during months when annual leave is popular. Errors of judgment are probably related to mental fatigue, and staff need to be aware how their performance may vary at different times, demanding a more disciplined systematic approach at night. Mistakes may also be ameliorated by

\section{Key messages}

- In low risk pregnancies the incidence of death due to intrapartum asphyxia is regarded as a sensitive measure of the quality of perinatal care

- Babies born at night and during summer months are at increased risk of death due to intrapartum asphyxia, raising concerns about variability in care around the time of delivery

- Errors of judgment may be related to mental fatigue. Staff need to be aware of how their performance may vary, and a more disciplined systematic approach at night may be needed

- Greater supervision by senior staff may be required at night and during summer months 
the increased use of shiftwork, but shifts need to be carefully designed to avoid an excessive disruption of circadian rhythms and consequent fatigue. In addition, greater supervision by senior staff may be required at night and during summer months.

We thank local coordinators and Mrs Judith Hopkins for their help with data collection. We are also indebted to Miss Z Guildea and Dr F Dunstan for statistical advice and Mr J King for his assistance.

Contributors: JHS initiated and developed the core idea and study design and participated in data collection, analysis, and writing the paper. JA contributed to data analysis and provided clinical advice on the manuscript. PHTC initiated and directs the all Wales perinatal survey. He participated in study design, data analysis, and writing the paper, and is the guarantor of the study.

Funding: The all Wales perinatal survey is funded by the Welsh Office.

Conflict of interest: None.

1 Macfarlane A, Mugford M. Birth counts: statistics of pregnancy and childbirth. London: HMSO, 1984

2 Gaffney G, Sellers S, Flavell V, Squier M, Johnson A. Case-control study of intrapartum care, cerebral palsy, and perinatal death. BMJ 1994;308: $743-50$.

3 Niswander K, Elbourne D, Redman C, Henson G, Chalmers I, Macfarlane A. Adverse outcome of pregnancy and the quality of obstetric care. Lancet 1984;ii:827-31.
4 Field DJ, Smith H, Mason E, Milner AD. Is perinatal mortality still a good indicator of perinatal care? Paediatr Perinat Epidemiol 1988;2:213-9.

5 Kiely JL, Paneth N, Susser M. Fetal-death during labour: an epidemiological indicator of level of obstetric care. Am J Obstet Gynecol 1985; 153:721-7.

6 Confidential Enquiry into Stillbirths and Deaths in Infancy. Report. London: Department of Health, 1993

7 Confidential Enquiry into Stillbirths and Deaths in Infancy. Fourth annual report. London: Maternal and Child Health Research Consortium, 1997.

8 British Postgraduate Medical Federation. Patterns of hospital medical staffing in obstetrics and gynaecology. London: HMSO, 1991.

9 All Wales Perinatal Survey and Confidential Enquiry into Stillbirths and Deaths in Infancy. Annual report 1996. Cardiff: Perinatal Survey Office, 1997.

10 Wigglesworth JS. Monitoring perinatal mortality-a pathophysiological approach. Lancet 1980;ii:684-6.

11 Keeling JW, MacGillivray I, Golding J, Wigglesworth J, Berry J, Dunn PM. Classification of perinatal death. Arch Dis Child 1989;64:1345-51.

12 Andrews J, Cotter M, Richards R, Lewis D. Report on maternal data/information aspects of the child health system. Cardiff: Welsh Office, 1996.

13 Meer L, Samra JS, Pilley C, Obhrai MS. Obstetric accidents. BMJ 1990; 301:118.

14 National Confidential Enquiry into Perioperative Deaths. Report 1994/1995. London: CEPOD, 1997

15 Driscoll P, Fothergill J, Touquet R. Risk management in accident and emergency medicine. Clinical risk management. London: BMJ Publishing Group, 1995.

16 Kapur N, House A. Job satisfaction and psychological morbidity in medical house officers. JR Coll Phys London 1997:31:162-7.

17 Gold DR, Rogacz S, Bock N, Tosteson TD, Baum TM, Speizer FE. Rotating shift work, sleep, and accidents related to sleepiness in hospital nurses. Am J Public Health 1992;82:1011-4.

(Accepted 21 November 1997)

\section{Effectiveness of screening older people for impaired vision in community setting: systematic review of evidence from randomised controlled trials}

Liam Smeeth, Steve Iliffe

Department of

Primary Care and

Population

Sciences, Royal Free

Hospital School of

Medicine and

University College

London Medical

School, London

NW3 2PF

Liam Smeeth,

research registrar

Steve Iliffe,

reader

Correspondence to: Dr L Smeeth

l.smeeth@ucl.ac.uk

BMJ 1998;316:660-3

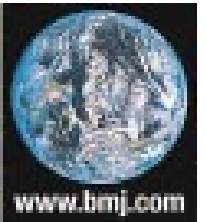

Full details of references $w 1-17$ appear on our website at www.bmj.com

\section{Abstract}

Objective: To assess whether population screening for impaired vision among older people in the community leads to improvements in vision. Design: Systematic review of randomised controlled trials of population screening in the community that included any assessment of vision or visual function with at least 6 months' follow up.

Subjects: Adults aged 65 or over.

Main outcome measure: Proportions with visual impairment in intervention and control groups with any method of assessing visual impairment.

Results: There were no trials that primarily assessed visual screening. Outcome data on vision were available for 3494 people in five trials of multiphasic assessment. All the trials used self reported measures for vision impairment, both as screening tools and as outcome measures. The inclusion of a visual screening component in the assessments did not result in improvements in self reported visual problems (pooled odds ratio $1.04: 95 \%$ confidence interval 0.89 to 1.22 ). A small reduction (11\%) in the number of older people with self reported visual problems cannot be excluded. Conclusions: Screening of asymptomatic older people in the community is not justified on present evidence. Visual impairment in this age group can usually be reduced with treatment. It is unclear why no benefit was seen. Further work is needed to clarify what interventions are appropriate for older people with unreported impairment of vision.

\section{Introduction}

The introduction of the sight test fee in 1990 increased concern about undetected visual problems in older people, ${ }^{1}$ and visual screening for older people in general practice was advocated. ${ }^{2}$ Renewed concern has been expressed recently by the Royal National Institute for the Blind ${ }^{3}$ and the Department of Health.

Since 1990 general practitioners have been required to offer an annual screening assessment to all patients aged 75 and over, ${ }^{5}$ specifically including an assessment of vision. While multiphasic screening of older people has been shown to be beneficial overall, ${ }^{6}$ exactly which procedures are effective is uncertain. The 75 and over programme is currently under review.

\section{Rationale for screening older people for visual problems}

Visual impairment is common among older people. In community based surveys of unselected older people undertaken in the United Kingdom, visual acuity of less than 6/12 has been found in around $2 \%$ of those aged 65 to 74 and around $20 \%$ of those aged 75 and over. ${ }^{8}$ This level of visual acuity is below the requirements for driving in the United Kingdom. ${ }^{10}$ Larger surveys have been performed in the United States, ${ }^{11-13}$ and, though the prevalence of reduced visual acuity is lower in one of these ${ }^{11}$ similar overall trends are seen. Various adverse factors have been reported in association with visual impairment. These include reduced functional status and quality of life, ${ }^{14-16}$ depression, ${ }^{16-18}$ and falls. ${ }^{19-21}$ 
Visual problems in older people may go unreported for several reasons, including decreased expectations in old age and a belief that nothing can be done to help, ${ }^{14}$ failure by the patient to recognise visual loss, ${ }^{22}$ or the presence of another handicap that dominates the perception of difficulties. ${ }^{23}$ Other possible inhibiting factors include fears about surgical treatment and $\operatorname{costs}^{24}$ and the stigma of blindness. ${ }^{25}$

How and why vision should be assessed was not specified in the 1990 general practitioner contract. ${ }^{5}$ The Royal College of General Practitioners advocates a simple question about visual function to identify unreported problems. ${ }^{26}$ Specific screening procedures for glaucoma or diabetic retinopathy have not been included in the over 75 programme nor in trials of multiphasic screening.

\section{Methods}

The research question was defined as, what is the effectiveness of population screening for visual impairment in improving vision among unselected older people (aged 65 or over) in a community setting, either alone or as part of a multiphasic assessment programme?

\section{Search methods}

A systematic Medline search for randomised controlled trials evaluating screening in older people was performed for the period 1966 to December 1996 by using a published optimally sensitive search strategy. ${ }^{27}$ The exploded (that is, including all sub-branches) MeSH terms "mass screening," "preventive health services," "eye diseases," and "diagnosis, eye," and the non-exploded $\mathrm{MeSH}$ terms "health promotion" and "geriatric assessment" were used. Titles and abstracts were searched for the words "geriatric" or "elderly" combined with any of "screening," "assessment," "health," "function," or "surveillance." Other textword searches used the words "macular degeneration," "cataract," and "presbyopia." Wild card characters were used to ensure all forms of words were included. At all stages articles about animals and children were excluded. The October 1997 Cochrane Library (which includes the Cochrane Controlled Trials Register and the Database of Abstracts of Reviews of Effectiveness) was also searched for both trials and relevant reviews. ${ }^{28}$ Other review articles and books were consulted. Bibliographies of all relevant articles were scanned. Experts in screening for older people and in ophthalmology were consulted.

\section{Inclusion criteria}

The inclusion criteria were in two stages. In the first stage, articles were included only if they were randomised controlled trials of either visual or multiphasic screening of unselected subjects in a community setting that included patients aged 65 and over. Trials of screening undertaken on selected groups of patients were excluded on the grounds that the results would not answer the question under review. Studies including adults aged under 65 only were also excluded. Because visual screening may have been only one small part of a multiphasic screening programme and data about visual outcomes may not have been included in published reports of trials, therefore, the named author for correspondence for all trials identified in the first stage was contacted (at their current addresses verified by telephone) to ask for any further unpublished data about visual screening tests used and visual outcomes. Non-responders were sent two reminders and were telephoned.

The second stage inclusion criteria were then applied to all the trials included from the first stage: the availability of any visual outcome data, whether formally tested or self reported; and a follow up of at least six months to allow intervention for detected visual problems.

\section{Study selection and data extraction}

The full texts of articles selected for retrieval and review from the abstracts and citations were obtained. A checklist of the first stage inclusion criteria was then applied by both authors independently. All criteria had to be met. After contact with the trial authors a structured data extraction form was used, again by both authors independently. Data was extracted as follows: setting; subjects; overall intervention; visual screening test(s) used; duration of follow up; and visual outcome measures and visual outcome data. Data about randomisation process, the degree of allocation concealment, and blinding of outcome assessors was also extracted. Authors were contacted for clarification if required. Disagreements between reviewers were discussed and a consensus reached on all articles.

\section{Critical appraisal}

There is empirical evidence that inadequate randomisation to intervention and control groups can affect the outcome of a trial..$^{29}$ In particular, it is important that the treatment assignment is known only after the decision has been taken for the patient to enter the trial. This is known as concealed allocation. Studies were therefore classified for allocation concealment by using previously developed categories: $\mathrm{A}=$ trials in which allocation appeared to be adequately concealed (for example, a central randomisation procedure); $\mathrm{B}=$ trials in which allocation concealment was unclear, either because the approach was not reported or in which the randomisation process did not match categories $\mathrm{A}$ or $\mathrm{C}$; and $\mathrm{C}=$ trials in which allocation concealment was inadequate (such as alphabetical use of surname). ${ }^{30} \mathrm{In}$ addition, data were extracted about the degree of blinding of outcome assessors in the trials.

\section{Outcome measures}

The aims of multiphasic screening of older people are broad-for example, to improve quality of life and reduce admission to hospital. Any benefit arising from the inclusion of a visual assessment, however, will necessarily be dependent on improved vision, which was therefore used as the outcome measure for this review. Any method of visual assessment (such as acuity chart, questions about vision, or measures of visual function) was accepted as an outcome measure. We felt that stricter inclusion would excessively limit the data included in the review.

\section{Analysis}

We used RevMan software. ${ }^{31}$ Heterogeneity between trials was tested for with $\chi^{2}$ test. Odds ratios were combined with the fixed effects Mantel-Haenszel method. The relative risk is presented as well as the odds ratio because it is more easily understood by some. ${ }^{32}$ 
Table 1 Randomised controlled trials of screening older people that included data on visual outcome: subjects, settings, and interventions. In all trials concealment of allocation was adequate (see text for details)

\begin{tabular}{|c|c|c|c|c|}
\hline Reference & Subjects and setting & Overall trial intervention & $\begin{array}{l}\text { Follow up } \\
\text { period }\end{array}$ & $\begin{array}{l}\text { Blinding of outcome } \\
\text { assessors }\end{array}$ \\
\hline Vetter $1984^{\text {w3 }}$ (UK) & $\begin{array}{l}\text { People aged over } 70 \text { living at home } \\
\text { registered with one of two general } \\
\text { practices }\end{array}$ & $\begin{array}{l}\text { Annual assessment at home by health visitor }(\mathrm{n}=577) v \\
\text { usual care }(\mathrm{n}=571)\end{array}$ & 2 years & Yes \\
\hline McEwan $1990^{\text {w9 }}$ (UK) & $\begin{array}{l}\text { People aged } 75 \text { and over registered } \\
\text { with one general practice }\end{array}$ & $\begin{array}{l}\text { Multiphasic nurse assessment at home }(n=151) v \text { usual } \\
\text { care }(n=145)\end{array}$ & 20 months & No \\
\hline Vetter $1992^{\text {w13 }}$ (UK) & $\begin{array}{l}\text { People aged over } 70 \text { living at home } \\
\text { registered with one general } \\
\text { practice }\end{array}$ & $\begin{array}{l}\text { Annual assessment at home by health visitor, specifically } \\
\text { aimed at reducing falls and fractures }(n=350) v \text { usual } \\
\text { care }(n=324)\end{array}$ & 4 years & Yes \\
\hline $\begin{array}{l}\text { Van Rossum } 1993^{\text {w14 }} \\
\text { (Netherlands) }\end{array}$ & $\begin{array}{l}\text { Respondents to postal invitation to } \\
\text { all people aged } 75-84 \text { living at } \\
\text { home in defined geographical area }\end{array}$ & $\begin{array}{l}\text { Four visits a year for three years by trained nurses } \\
(n=292) v \text { usual care }(n=288)\end{array}$ & 3 years & Yes \\
\hline Wagner $1994^{\text {w16 }}$ (US) & $\begin{array}{l}\text { Health maintenance organisation } \\
\text { customers aged } 65 \text { and over }\end{array}$ & $\begin{array}{l}\text { Multiphasic assessment by nurse, which included a } \\
\text { visual assessment }(n=635) \vee v \text { general health promotion } \\
\text { visit with no visual assessment }(n=317) v \text { usual care } \\
\text { ( } n=607)\end{array}$ & 2 years & Postal questionnaires used \\
\hline
\end{tabular}

Table 2 Visual screening methods and outcome measures

\begin{tabular}{|c|c|c|}
\hline Reference & Visual screening method & Visual outcome measure \\
\hline Vetter $1984^{\mathrm{w} 3}$ (UK) & Two questions about glasses and difficulty seeing & $\begin{array}{l}\text { Proportion with positive response to question "Do you have any } \\
\text { difficulty seeing (even when wearing your glasses)" }\end{array}$ \\
\hline McEwan $1990^{\text {w9 }}$ (UK) & Series of questions about vision and glasses & $\begin{array}{l}\text { Proportion who "always" or "quite often" had difficulty reading } \\
\text { ordinary newsprint (with glasses if worn) }\end{array}$ \\
\hline Vetter $1992^{\text {w13 }}$ (UK) & As Vetter 1984, with additional question about recent eye test & As Vetter $1984^{\mathrm{w} 3}$ \\
\hline $\begin{array}{l}\text { Van Rossum } 1993^{\text {w14 }} \\
\text { (Netherlands) }\end{array}$ & $\begin{array}{l}\text { One question "How do you assess your vision at present?" } \\
\text { Possible answers: excellent, good, fair, not so good, or bad }\end{array}$ & $\begin{array}{l}\text { Proportion answering "fair," "not so good," or "bad" to } \\
\text { screening question at end of study }\end{array}$ \\
\hline Wagner $1994^{\text {w16 }}$ (US) & $\begin{array}{l}\text { Simple questions about visual function and use of glasses in } \\
\text { postal questionnaire }\end{array}$ & $\begin{array}{l}\text { Proportion reporting visual problems on repeated mailed } \\
\text { questionnaire at } 2 \text { years }\end{array}$ \\
\hline
\end{tabular}

\section{Results}

In total 2246 citations and abstracts were screened, and 147 full text articles were reviewed in detail. Seventeen trials met the first stage inclusion criteria, all of which were trials of multiphasic screening. The reference details are given on the web. ${ }^{\text {w1-17 }}$ There were no trials that primarily assessed visual screening. Requests for further information led to replies from authors of 16 of the 17 trials. Five trials met the final inclusion criteriathat is, visual outcome data with follow up of at least 6 months. ${ }^{\mathrm{w} 3 \mathrm{w} 9 \mathrm{w} 13 \mathrm{w} 14 \mathrm{w} 16}$ These trials are summarised in table 1.

All five trials adequately concealed randomisation. Regarding blinding of outcome assessors, the trial participants were aware of whether they had received a screening assessment. Thus, despite attempts to blind the outcome assessors, which arm of the trial subjects were in could clearly emerge during the face to face assessments of outcome. This phenomenon was noted

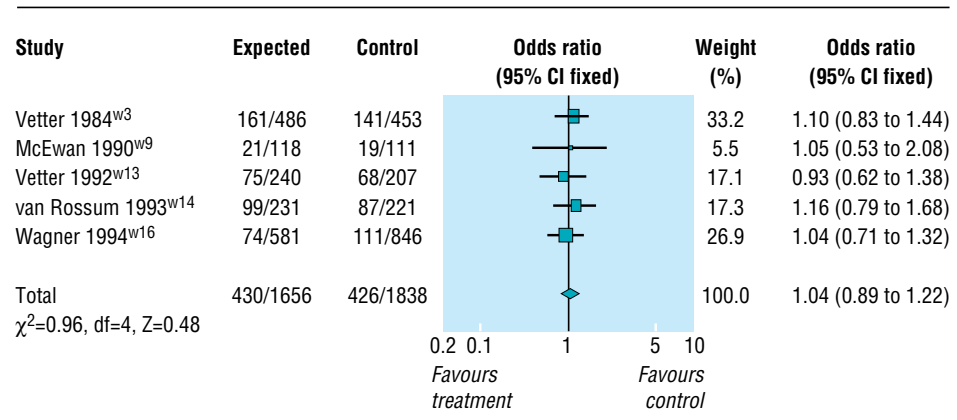

Outcome data: individual and pooled odds ratios for visual screening as part of multiphasic screening package versus standard care. Outcome was not seeing well, as defined by each trial by Vetter in two trials ${ }^{\mathrm{w} 3 \mathrm{w}^{13}}$ and led McEwan to consider such blinding impossible. ${ }^{\mathrm{w} 9}$

Individuals in the trial by Wagner and colleagues were recruited from a health maintenance organisation and may have differed in their overall baseline health from the general population. ${ }^{\mathrm{w} 16}$ This trial had three arms. For the purposes of our review subjects in the two arms who did not receive any form of visual screening assessment were analysed together as control patients.

Table 2 shows the visual assessment methods and outcome measures. All the trials used self reported measures to assess impaired vision, both as the screening assessment and as the outcome measure.

\section{Effects of screening on visual impairment}

Statistical testing showed no evidence of heterogeneity of effect in the five trials $\left(\chi^{2}=0.96, \mathrm{df}=4, \mathrm{P}=0.92\right)$. When odds ratios were pooled there was no reduction in the proportion of individuals with visual impairment as a result of screening (pooled odds ratio 1.04; $95 \%$ confidence interval 0.89 to 1.22). The figure shows the outcome data, and individual and pooled odds ratios. The pooled relative risk for visual impairment was 1.03 (0.92 to 1.15$)$.

\section{Discussion}

The evidence from randomised controlled trials does not support the inclusion of an assessment of vision in regular multiphasic assessment programmes for unselected older people in a community setting or visual screening in primary care. ${ }^{2}$ Although a reduction of $11 \%$ in the number of older people with visual impairment cannot be excluded, even this figure is disappointingly low. 
Results from community surveys in the over 75 age group suggest that over half the visual impairment in this age group could potentially be reduced with treatment, notably by cataract surgery or refractive correction. ${ }^{8}{ }^{13}$ In light of this the lack of improvement seen in these trials is somewhat surprising and cannot be explained from the data presented. Several factors, however, may have contributed. Firstly, the visual assessment was only one component of the screening package in all five trials, and visual screening performed in isolation may have produced a greater effect. This hypothesis was previously suggested as an explanation of the lack of effectiveness of screening for visual impairment seen in a trial of a multiphasic screening assessment among middle aged men. ${ }^{33}{ }^{34} \mathrm{In}$ clinical practice, however, screening for visual impairment is highly likely to be one part of a broader screening package, and therefore an assessment of effectiveness within a broader package is the most pragmatically useful measure. Secondly, the people who reported visual problems when prompted to do so in a screening programme may not have perceived their previously unreported visual impairment as a "need" for intervention. Lastly, there is evidence that considerable obstacles exist to improving visual impairment among older people. In the United Kingdom fear of costs has been repeatedly cited by a proportion of older people as a barrier to attending an optometrist and obtaining glasses.. ${ }^{342435}$ In addition, ophthalmic services are unable to meet current demands for treatment, with long waiting lists for cataract surgery in many areas. ${ }^{36}$

The aim of population screening of older people for visual impairment is presumably to discover visual impairment in those who are not presenting to the health services and to offer them interventions to improve their vision. Further work is required, however, to determine the needs of older people with unreported visual problems. Before population screening can be effective, existing obstacles to the reduction of visual impairment among older people must be overcome.

We thank all the study authors who responded to requests for additional information. R McEwan, $\mathrm{N}$ Vetter, $\mathrm{E}$ van Rossum, and E Wagner provided unpublished data used in this review.

Contributors: LS developed the original idea, searched the literature, and undertook the analysis. SI had the original idea and provided supervision throughout. Both authors critically appraised the trials, extracted data, wrote the paper, and approved the final manuscript. LS is the guarantor of the paper.

Funding: LS was a research registrar on the London Academic Training Scheme (LATS), 1996-7.

Conflict of interest: None.

1 Rosenthal A. High street eye tests. BMJ 1990;300:695-6

2 Hitchings RA. Visual disability and the elderly. BMJ 1989;298:1126-7.

3 Grindey S, Winyard S. Losing sight of blindness. London: RNIB, 1997.

4 Department of Health. The National Health Service: a service with ambitions London: HMSO, 1996

5 Department of Health and the Welsh Office. General practice in the National Health Service. A new contract. London: Department of Health, 1989

6 Stuck AK, Siu AL, Wieland GD, Adams J, Rubenstein LZ. Comprehensive geriatric assessment: a meta-analysis of controlled trials. Lance 1993;342:1032-6.

7 Iliffe S, Gould M, Wallace P. Evaluation of the over 75 checks in general practice. Report to the NHS Executive. London: Department of Primary Care and Population Sciences, University College London Medical School and and Population Sciences, University College Londo

8 Wormald RP, Wright LA, Courtney P, Beaumont B, Haines AP. Visual problems in the elderly population and implications for services. $B M J$ 1992;304:1226-9.

9 Lavery JR, Gibson JM, Shaw DE, Rosenthal AR. Vision and visual acuity in an elderly population. Ophthalmic Physiol Opt 1988;8:390-3.

10 Drivers Medical Group. At a glance guide to current medical standards of fit ness to drive. Swansea: DVLA, 1996.
Key messages

- Impaired vision is common among older people and has a variety of adverse associations

- General practitioners are currently obliged to offer an annual assessment of vision as part of the 75 and over programme

- Evidence for effectiveness of visual screening is lacking, but a small beneficial effect cannot be excluded

- The continued inclusion of screening for impaired vision in screening programmes for older people is not supported by the evidence

- Further work is needed to clarify appropriate interventions for older people with unreported visual impairment

11 Leibowitz HM, Krueger DE, Maunder LR, Milton RC, Kini MM, Kahn HA, et al. The Framingham eye study monograph. Surv Ophthalmol 1980;24(suppl):335-610.

12 Tielsch JM, Sommer A, Witt K, Katz J, Royall RM. Blindness and visual impairment in an American urban population. The Baltimore eye survey. Arch Ophthalmol 1990;108:286-90.

13 Klein R, Klein BE, Linton KL, De MD. The Beaver Dam eye study: visual acuity. Ophthalmology 1991;98:1310-5.

14 Landes R, Popay J. "My sight is poor but I'm getting on now": The health and social care needs of older people with visual problems. Health Soc Care 1993;1:325-35.

15 Scott IU, Schein OD, West S, Bandeen-Roche K, Enger C, Folstein MF. Functional status and quality of life measurement among ophthalmic patients. Arch Ophthalmol 1994;112:329-35.

16 Carabellese C, Appollonio I, Rozzini R, Bianchetti A, Frisoni GB, Frattola L, et al. Sensory impairment and quality of life in a community elderly population. J Am Geriatr Soc 1993;41:401-7.

17 Rovner BW,Zisselman PM, Shmuely-Dulitzki Y. Depression and disability in older people with impaired vision: a follow-up study. J Am Geriatr Soc 1996;44:181-4.

18 Jones DA, Vetter NJ, Victor CV. Visual disability and associated factors in the elderly. Health Visitor 1987;60:256-7.

19 Brocklehurst JC, Exton-Smith AN, Lempert-Barber SM, Hunt LP, Palmer MK. Fracture of the femur in old age: a two centre study of associated clinical factors and the cause of the fall. Age Ageing 1978;7:7-15.

20 Felson DT, Anderson JJ, Hannan MT, Milton RC, Wilson MC, Kiel DP Impaired vision and hip fracture, the Framingham study. J Am Geriatr Soc 1989:37:495-500

21 Grisso JA, Kelsey JL, Strom BL, Chiu GY, Maislin G, O'Brien LA, et al. Risk factors for falls as a cause of hip fracture in women. The Northeast Hip Fracture Study Group. N Engl J Med 1991:324:1326-31.

22 Long CA, Holden R, Mulkerrin E, Sykes D. Opportunistic screening of visual acuity of elderly patients attending outpatient clinics. Age Ageing 1991;20:392-5.

23 Cullinan TR. The epidemiology of visual disability. Studies of visually disabled people in the community. Canterbury: University of Kent, 1977. (Health Services Research Unit Report No 28.

24 Reinstein DZ, Dorward NL, Wormald RP, Graham A, O'Connor I, Charlton RM, et al. "Correctable undetected visual acuity deficit" in patients aged 65 and over attending an accident and emergency department. Br J Ophthalmol 1993;77:293-6.

25 Cullinan TR. Visual disability in the elderly. London: Croom Helm, 1986.

26 Williams EI, Wallace P. Health checks for people aged 75 and over. London: Royal College of General Practitioners, 1993.

27 Dickersin K, Scherer E, Lefebvre C. Identification of relevant studies for systematic reviews. BMJ 1994;309:1286-91.

28 The Cochrane Library [database on disk and CD-ROM]. Cochrane Collaboration, 1997, Issue 4. Oxford: Update Software, 1997. Updated quarterly.

29 Schulz KF, Chalmers I, Hayes RJ, Altman DG. Empirical evidence of bias. Dimensions of methodological quality associated with estimates of treatment effects in controlled trials. JAMA 1995;273:408-12.

30 Mulrow CD, Oxman AD, eds. Critical appraisal of studies. Cochrane Collaboration Handbook [updated 1 March 1997]; Section 6. The Cochrane Library [database on disk and CD ROM]. Cochrane Collaboration. Oxford: Update Software, 1997. Updated quarterly.

31 Update Software. RevMan. Version 3.0 for Windows. Oxford: Update Software, 1996.

32 Sackett DL, Deeks IJ, Altman DG. Down with odds ratios! [EBM note.] Evidence Based Med 1996;1:164-6.

33 The South-East London Screening Study Group. A controlled trial of multiphasic screening in middle-age: results of the south-east London screening study. Int J Epidemiol 1977;6:357-63.

34 Stone DH, Shannon DJ. Screening for impaired visual acuity in middle age in general practice. $B M J 1978 ; 2: 859-61$

35 Webster E WA, Barnes G. Eye tests in the elderly: factors associated with attendance and diagnostic yield in non-attenders. I $R$ Soc Med 1992;85:614-6.

36 NHS Centre for Reviews and Dissemination, University of York. Management of cataract. Effective Health Care 1996;2(3).

(Accepted 18 November 1997) 


\title{
Association of glutamine 27 polymorphism of $\boldsymbol{\beta}_{2}$ adrenoceptor with reported childhood asthma: population based study
}

\author{
E Hopes, C McDougall, G Christie, J Dewar, A Wheatley, I P Hall, P J Helms
}

Department of Child Health, Medical School, University of Aberdeen,

Aberdeen

AB25 2ZD

E Hopes,

PhD student

C McDougall,

medical student

G Christie,

research fellow

P J Helms,

professor

Department of

Medicine,

University Hospital,

Queen's Medical

Centre, Nottingham

NG7 2UH

J Dewar,

research fellow

A Wheatley,

PhD student

I P Hall,

reader

Correspondence to:

Professor Helms

p.j.helms@abdn.ac.uk

BMJ 1998;316:664
The prevalence of asthma in children has doubled over the past 25 years. ${ }^{1}$ Two common polymorphisms exist in the $\beta$ adrenoceptor at amino acids 16 (glycine for arginine) and 27 (glutamic acid for glutamine). Both are functionally relevant in cultured cells, with the glycine 16 form of the receptor showing enhanced downregulation and the glutamic acid 27 form showing attenuated downregulation after exposure to $\beta$ agonists. ${ }^{2}$ The glutamine 27 polymorphism is associated with raised $\operatorname{IgE}$ concentrations in families with a history of asthma, and with increased reactivity of the airways in people with asthma. ${ }^{34}$ We measured the prevalence of these polymorphisms in a random population of children to identify their importance in the expression of reported asthma.

\section{Subjects, methods, and results}

We approached children between the ages of 5 and 15 years (mean 10.5 years) and an accompanying parent who were attending the accident and emergency department of the Royal Aberdeen Children's Hospital. Approval from an ethics committee and written consent were obtained from the parents and participating children, and 425 (97\%) of 438 agreed to participate. After completing a brief questionnaire each child provided a mouth wash sample $(10 \mathrm{ml}$ of boiled distilled water). ${ }^{1}$ From the resulting suspension of buccal epithelial cells DNA was extracted, and the $\beta_{2}$ adrenoceptor polymorphisms were identified using the polymerase chain reaction and an allele specific oligonucleotide assay. ${ }^{3}$ Frequency tables and Pearson's $\chi^{2}$ test were used for bivariate comparisons and logistic regression employed in the multivariate analysis.

Complete information including phenotype information on both parents and genotype information in children was available for 410 children with genotyping data in 419. The childhood prevalence of reported asthma (104 out of $425,24 \%)$ was similar to that observed in a recent postal questionnaire study from the same population. ${ }^{5}$

Thirty nine were arginine 16 homozygotes, 179 were glycine 16 homozygotes, and 201 were heterozygotes. Ninety three were glutamic acid 27 homozygotes, 107 were glutamine 27 homozygotes, and 219 were heterozygotes for the two. The two polymorphisms were in partial linkage disequilibrium. The allelic prevalences of the $\beta_{2}$ polymorphisms in this child population were virtually identical with those found in a random sample of adults in Nottingham (unpublished data). Both polymorphisms were in Hardy-Weinburg equilibrium.

Genotype at position 16 was not associated with reported asthma. Both homozygosity and heterozygosity for the glutamine 27 polymorphism were associated with reported asthma (table), with a significant association between the presence of this allele and reported asthma $\left(\chi^{2}=4.38, \mathrm{df}=1, \mathrm{P}=0.04\right)$. On logistic
Genotypes at position 27 and reported asthma

\begin{tabular}{lccc} 
& $\begin{array}{c}\text { No } \\
\text { asthma }\end{array}$ & $\begin{array}{c}\text { Reported } \\
\text { asthma }\end{array}$ & $\begin{array}{c}\text { Totals for position } \\
\text { 27 genotypes }\end{array}$ \\
\hline Glutamine 27 homozygote & 83 & $24(22 \%)$ & 107 \\
\hline $\begin{array}{l}\text { Glutamine and glutamate } \\
\text { heterozygote }\end{array}$ & 156 & $63(30 \%)$ & 218 \\
\hline $\begin{array}{l}\text { Glutamate 27 homozygote } \\
\text { nate }\end{array}$ & 78 & $15(16 \%)$ & 93
\end{tabular}

regression analysis and taking other known factors into account (sex, maternal asthma, reported hay fever, and eczema) the glutamine 27 allele conferred an independent increased risk of reported asthma (odds ratio 2.18, confidence interval 1.13 to $4.23, \mathrm{P}=0.02)$. Conversely, homozygosity for the glutamic acid 27 polymorphism had a lower risk (odds ratio $0.46,(0.24$ to 0.89$)$ ). Of the 104 children with reported asthma, 47 were also reported to have coexisting hay fever or eczema, or both. When this subpopulation was included in a secondary analysis, the modifying effect of glutamic acid 27 was of a similar order $\left(\chi^{2}=9.56, \mathrm{df}=4, \mathrm{P}=0.05\right)$.

\section{Comment}

The finding that the glutamic acid 27 polymorphism may be associated with a decreased prevalence of reported asthma in childhood is consistent with its effects on IgE concentration and non-specific bronchial reactivity. ${ }^{3}$ Interestingly, this polymorphism was not associated with asthma in adult populations, ${ }^{3}$ in whom IgE may be a less important determinant of the asthma phenotype. Whether the glutamine for glutamic acid polymorphism at position 27 determines the asthma phenotype in children or whether it is in linkage disequilibrium with another gene, perhaps in the nearby $\mathrm{T}$ helper 2 cytokine gene cluster on chromosome 5q, remains to be established.

Contributors: PJH coordinated and supervised the study and, in discussion with I P Hall, had the original idea for it. PJH and IPH are joint guarantors for the study. $\mathrm{CMcD}$ recruited the families, applied the questionnaire, obtained the mouth wash samples, and, together with $\mathrm{JD}, \mathrm{AW}$, and $\mathrm{EH}$, performed the laboratory analyses under the supervision of IPH. GC contributed to the background review and data analysis. The paper was written jointly by $\mathrm{PJH}, \mathrm{EH}$, and IPH.

Funding: Aberdeen Royal Hospitals NHS Trust (additional contribution for teaching and research), studentships and National Asthma Campaign.

Conflict of interest: None.

1 Ninan TK, Russell G. Respiratory symptoms and atopy in Aberdeen schoolchildren: evidence from two surveys 25 years apart. BMJ 1992;304:873-5

2 Green SA, Turki J, Bejarano P, Hall I, Liggett SB. Influence of $\beta_{2}$-adrenergic receptor genotype on signal transduction in human airway smooth muscle cells. Am J Respir Cell Mol Biol 1995;13:25-33.

3 Dewar JC, Wilkinson J, Wheatley A, Thomas NS, Doulle I, Morton N, et al. The glutamine $27 \beta_{2}$-adrenoceptor polymorphism is associated with elevated IgE levels in asthmatic families. J Allergy Clin Immunol 1997;100:261-5.

4 Hall IP, Wheatley A, Wilding P, Liggett SB. Association of the Glu27 $\beta_{22}$ polymorphism with lower airway reactivity in asthmatic subjects. Lancet 1995;345:1213.

5 Omran M, Russell G. Continuing increase in respiratory symptoms and atopy in Aberdeen schoolchildren. BMJ 1996;312:34.

(Accepted 29 July 1997) 


\title{
Parental history of gastric or duodenal ulcer and prevalence of Helicobacter pylori infection in preschool children: population based study
}

\author{
Hermann Brenner, Dietrich Rothenbacher, Günter Bode, Guido Adler
}

Helicobacter pylori infection is present in almost all patients with duodenal ulcers and $80-90 \%$ of patients with gastric ulcers, ${ }^{1}$ whereas the prevalence of infection among young adults without a history of ulcer is fairly low in Western countries. ${ }^{2}$ To investigate the importance of transmission from parent to child we assessed the relation between a parent's history of gastric or duodenal ulcer and infection with $H$ pylori in his or her offspring in a large population of preschool children.

\section{Subjects, methods, and results}

A cross sectional study was carried out among 1201 preschool children living in Ulm, a city of about 100000 inhabitants located in southern Germany. The children had a medical examination before starting school in 1996. Details of the study design are reported elsewhere. ${ }^{3}$ In brief, a urea breath test using carbon-13 was conducted to determine whether the children had an active infection of $H$ pylori. One to two weeks before their child's examination a standardised questionnaire was sent to the parents to ascertain whether they had had a gastric or duodenal ulcer diagnosed by a doctor. The questionnaire also included detailed information on other potential risk factors for $H$ pylori infection, such as housing conditions, family demographics, and socioeconomic factors. The prevalence of $H$ pylori infection in the children of parents with a history of gastric or duodenal ulcer was compared with that in children whose parents had no such history. Multiple logistic regression was used to adjust for known or suspected risk factors that might confound the results. ${ }^{4}$

Overall, 945 of the 1201 children participated in the study (response rate 79\%). To minimise false negative results from the urea breath test, 82 children were excluded because they had received antibiotic treatment within the preceding 4 weeks. A history of gastric or duodenal ulcer was reported in 22 mothers and 28 fathers (table). Overall, 118 (14\%) of the 863 children were infected with $H$ pylori. Among children whose mothers had a history of gastric or duodenal ulcer the prevalence of infection was more than double that among those whose mothers had no such history (odds ratio 2.4 (95\% confidence interval 0.9 to 6.4 )). The association was significant after adjustment for known or suspected risk factors of infection by multiple logistic regression (11.7 (3.8 to 36.2); $\mathrm{P}<0.0001$ ) (table). No significant association was seen between a paternal history of ulcer and active infection in children.

\section{Comment}

The difference between the prevalence of infection in children whose mothers are infected with $H$ pylori and that in children whose mothers are not infected is

Prevalence of Helicobacter pylori infection in 863 preschool children according to parental history of duodenal or gastric ulcer

\begin{tabular}{|c|c|c|c|c|}
\hline \multirow[b]{2}{*}{ History of ulcer in parent } & \multirow[b]{2}{*}{$\begin{array}{l}\text { No of } \\
\text { children }\end{array}$} & \multirow[b]{2}{*}{$\begin{array}{c}\text { No }(\%) \text { infected with } \\
\text { H pylori }\end{array}$} & \multicolumn{2}{|c|}{ Odds ratio $(95 \% \mathrm{CI})$} \\
\hline & & & Crude & Adjusted ${ }^{*}$ \\
\hline \multicolumn{5}{|l|}{ Mother: } \\
\hline No & 841 & $112(13)$ & 1.0 & 1.0 \\
\hline Yes & 22 & $6(27)$ & $2.4(0.9$ to 6.4$)$ & 11.7 (3.8 to 36.2$)$ \\
\hline$P$ value for comparison & & & 0.07 & $<0.0001$ \\
\hline \multicolumn{5}{|l|}{ Father: } \\
\hline No & 835 & $113(14)$ & 1.0 & 1.0 \\
\hline Yes & 28 & $5(18)$ & 1.4 (0.5 to 3.7$)$ & $1.6(0.4$ to 5.5$)$ \\
\hline$P$ value for comparison & & & 0.51 & 0.49 \\
\hline
\end{tabular}

*Adjusted for nationality, mother's education, father's education, housing density, birth order, history of breast feeding, attendance at nursery, antibiotic treatment, and history of ulcer in the other parent.

likely to be even larger than the difference shown by the mothers with a history of ulcer in this study.

In theory, the relation between a parent's history of ulcer and $H$ pylori infection in his or her offspring may be explained by several mechanisms, including common environmental or genetic factors that influence susceptibility to infection. ${ }^{5}$ However, these factors imply that a history of ulcer in the mother or father will be similarly associated with infection in a child. As mothers typically have closer contact with their children, a more plausible explanation for the observed patterns would be transmission between mother and infant. Our results would also be consistent with the hypotheses that the transmission may be influenced by the presence of ulcer or that $H$ pylori strains causing peptic ulcer may be more infective than other strains.

We thank Dietlind Wehrhahn and Ingrid Wörner and the staff of the Public Health Service of Ulm for their support in this study. Contributors: HB had the original idea for the study, coordinated the design and field work, conducted the analysis, and wrote the paper; he will act as guarantor of the study. DR, GB, and GA participated in the design, field work, and writing of the paper. Regina Gommel and Gabriele Berg contributed to the design and field work.

Funding: No external funding.

Conflict of interest: None.

1 NIH Consensus Conference. Helicobacter pylori in peptic ulcer disease. JAMA 1994;272:65-9.

2 Goodman KJ, Correa P. The transmission of Helicobacter pylori. A critical review of the evidence. Int J Epidemiol 1995;24:875-87.

3 Rothenbacher D, Bode G, Berg G, Gommel R, Gonser T, Adler G, et al. Prevalence and determinants of Helicobacter pylori infection in pre-school children-a population based study from Germany. Int $J$ Epidemiol (in press).

4 Webb PM, Knight T, Greaves S, Wilson A, Newell DG, Elder J, et al. Relation between infection with Helicobacter pylori and living conditions in childhood: evidence for person to person transmission in early life. $B M J$ 1994;308:750-3.

5 Malaty HM, Engstrand L, Pedersen NL, Graham DY. Helicobacter pylori infection: genetic and environmental influences. A study of twins. Ann Intern Med 1994;120:982-6.

(Accepted 5 August 1997)
Department of Epidemiology, University of Ulm, D-89069 Ulm, Germany Hermann Brenner, professor of epidemiology Dietrich Rothenbacher, assistant professor in epidemiology Department of Internal Medicine I, University of Ulm Günter Bode, assistant professor in internal medicine Guido Adler, professor in internal medicine

Correspondence to: Dr Brenner

BMJ 1998;316:665 


\title{
Relation of aplastic anaemia to use of chloramphenicol eye drops in two international case-control studies
}

\author{
Bengt-Erik Wiholm, Judith Parsells Kelly, David Kaufman, Surapol Issaragrisil, Micha Levy, \\ Theresa Anderson, Samuel Shapiro
}

Medical Pharmacoepidemiology Unit, Department of Clinical

Pharmacology,

Karolinska Institute,

Huddinge

University Hospital,

S-141 86 Huddinge,

Sweden

Bengt-Erik Wiholm, associate professor

Slone

Epidemiology Unit, Boston University

School of Medicine,

Brookline,

MA 02146, USA

Judith Parsells Kelly, epidemiologist

David Kaufman, assistant director

Theresa Anderson, study coordinator

Samuel Shapiro,

director

Mahidol University, Bangkok, Thailand Surapol Issaragrisil, professor

Hadassah

University Hospital, Jerusalem, Israel

Micha Levy,

professor

Correspondence to: Professor Wiholm, Medical Products Agency, PO Box 26, S-75103 Uppsala,

Sweden

beje.wiholm@mpa.se

BMJ 1998;316:666
Although the use of chloramphenicol eye drops is thought to cause aplastic anaemia, ${ }^{1}$ this side effect has not been studied critically. We examined the use of ocular chloramphenicol in two population based case-control studies conducted with the same methods. ${ }^{23}$

\section{Subjects, methods, and results}

The data from the international granulocytosis and aplastic anaemia study were collected over varying times from 1980 to 1986 in Israel and in Ulm and Berlin (Germany), Milan (Italy), Budapest (Hungary), Sofia (Bulgaria), and Stockholm and Uppsala (Sweden); the total base population was about 19 million. ${ }^{2}$ Data collection continued independently in Sweden until 1992. The Thai study was conducted from 1989 to 1994 in Bangkok and from 1990 to 1994 in Khonkaen and Songkla; the total population was about 21 million.

In both studies patients with aplastic anaemia were identified by regular telephone contacts with all hospitals in the study regions. Cases were patients whose peripheral blood counts and bone marrow histology met accepted diagnostic criteria ${ }^{2}$; each diagnosis was confirmed by a panel of haematologists blinded to drug exposures. Controls matched for age and sex were selected from among patients admitted to the same hospitals within 3 months for reasons judged to be independent of antecedent drug use-for example acute trauma. ${ }^{3}$ Data on exposure to chloramphenicol were obtained by interview and included detailed histories of all drug use (including topical drugs) in the 6 months before admission; lists of indications for use and trade names of drugs of particular interest were used to help recall. The time of onset of aplastic anaemia could not be determined with precision because some symptoms, such as fatigue, are vague. Therefore, any use in the 5 month period from 6 months to 1 month before admission was judged to be aetiologically relevant.

There were 426 cases and 3118 controls. None of the cases had used chloramphenicol eye drops, but seven of the controls had used them (table ${ }^{1}$ ). The upper

Exposure to chloramphenicol in seven controls

\begin{tabular}{llcccccc} 
Control No & Region & $\begin{array}{c}\text { Age } \\
\text { (years) }\end{array}$ & Sex & Route & Frequency & $\begin{array}{c}\text { Last use } \\
\text { before } \\
\text { admission }\end{array}$ & Duration \\
\hline 1 & Thailand & 9 & M & Ocular & Daily & 3rd month & 2 days \\
\hline 2 & Thailand & 21 & M & Ocular & Daily & 4th month & 1 day \\
\hline & & & & Oral & Daily & 2nd month & 3 days \\
\hline 4 & Thailand & 63 & F & Ocular & Daily & 5th month & 5 days \\
\hline 5 & Thailand & 29 & F & Ocular & Daily & 3rd month & 3 days \\
\hline 6 & Israel & 66 & M & Ocular & Daily & 1 day & 2 months \\
\hline 7 & Sweden & 34 & F & Ocular & Occasional & 1 day & 5 years \\
\hline & Israel & 19 & M & Ocular & Daily & 3rd month & 3 days \\
\hline
\end{tabular}

$95 \%$ confidence limit for a relative risk of zero ${ }^{4}$ was 5.1 . Five of the exposed controls $(0.2 \%)$ had been exposed for $\geqslant 3$ days.

\section{Comment}

We conducted two population based studies using virtually identical protocols representing about 185 million person years of observation in industrialised and developing countries. Among more than 400 cases of aplastic anaemia there was no use of chloramphenicol eye drops. Although there was no evidence of an association the prevalence of use among the controls was low, and the possibility of some increase in risk cannot be excluded.

Bias is unlikely to account for the findings, since associations were found in these data for several other previously suspected drugs. ${ }^{23}$ Information bias, in particular, is improbable: chloramphenicol has long been suspected as a cause of aplastic anaemia, and the likely result of any such bias would have been an overestimation of the risk. Definition of the appropriate window of exposure for drug induced aplastic anaemia is more problematic. Because of the insidious onset of aplastic anaemia we excluded any drug use that started in the month before admission.

Our data provide no support to the claim that chloramphenicol eye drops increase the risk of aplastic anaemia. ${ }^{1}$ The literature lends only weak support for causality, being based on a few single case reports that are often inadequately investigated and have other possible causes. The recommendation that chloramphenicol eye drops should be avoided because of an increased risk of aplastic anaemia ${ }^{1}$ is not well founded.

Contributors: BEW had the idea for the present analysis, initiated the work and drafted the paper.JPK did the combined analysis of the two studies. The international granulocytosis and aplastic anaemia study was designed by SS, ML, who was the chairman of the study, and DK. The Thai study was designed by SI, who was the principal investigator, DK and SS. Both studies were coordinated and quality controlled by TA. All authors contributed ideas and helped with the final writing of the paper. BEW and DK are guarantors of the work.

Funding: The present analysis had no external funding. The study was primarily sponsored by Hoechst, Frankfurt, Germany, with additional support from Apoteksbolaget, Sweden, and the governments of Hungary and Bulgaria. The Thai study was sponsored by grant number R01-HL35068 from the US National Heart Lung and Blood Institute.

1 Doona M, Walsh JB. Use of chloramphenicol as ocular eye medication: time to cry halt? BMJ 1995;310:1217-8.

2 Kaufman DW, Kelly JP, Levy M, Shapiro S. The drug etiology of agranulocytosis and aplastic anemia. New York: Oxford University Press, 1991.

3 Issaragrisil S, Kaufman DW, Anderson T, Chansung K, Thamprasit T, Sirijiachai J, et al. Low drug attributability of aplastic anemia in Thailand. Blood 1997;89:4034-9.

4 Thomas DG. Exact confidence limits for the odds ratio in a 2x2 table. Appl Stat 1971;20:105-10

(Accepted 21 July 1997) 


\section{Risk of serious haematological toxicity with use of chloramphenicol eye drops in a British general practice database}

Tim Lancaster, Ann Marie Swart, Hershel Jick

An editorial in the $B M J$ recommended discontinuation of the routine use of chloramphenicol eye drops largely on the basis of case reports suggesting an association between their use and serious haematological toxicity, particularly aplastic anaemia. ${ }^{1}$ Although this recommendation has been challenged, the debate has not been informed by reliable estimates of the size of any risk. ${ }^{2}$

Around 400 general practices in the United Kingdom contribute anonymised data to the general practice research database. They record prescriptions and diagnoses from consultations and hospital letters. Use of the data for drug safety studies is well validated. ${ }^{3}$ In particular, previous studies have shown that it can be used reliably to detect associations between drug exposure and haematological toxicity. ${ }^{4}$ We used the database to describe prescribing patterns of chloramphenicol eye drops and to estimate the risk of aplastic anaemia after their use.

\section{Subjects, methods, and results}

We identified all patients who received at least one prescription for chloramphenicol eye drops between January 1988 and April 1995. We reviewed the computer records of patients with a new diagnosis of any of the following conditions occurring up to 90 days after such a prescription: aplastic anaemia, thrombocytopenia, agranulocytosis, leucopenia or neutropenia, unspecified white blood cell disorders, blood dyscrasia (International Classification of Diseases, eighth revision, codes 284.9, 287.1, 288.0, 288.1, 288.9, 289.9).

A total of 442543 patients received 674148 prescriptions for chloramphenicol eye drops. 314205 patients $(71 \%)$ received one prescription; 115061 $(26 \%)$ had between two and four prescriptions, and $13276(3 \%)$ had five or more. Use was higher in the younger age groups. Around 30\% of children aged 0-9 years received one or more prescriptions compared with $8 \%$ of those aged $10-44$ years and $5 \%$ of those aged 45 or more.

We identified three patients with serious haematological toxicity and one who developed mild, transient leucopenia that was not considered serious. One of the serious cases, a boy with epilepsy, was admitted to hospital with red cell aplasia 72 days after a prescription for chloramphenicol eye drops. He had received four prescriptions over a five year period, two of them in the three months preceding admission. He had stopped taking lamotrigine six weeks before because he had developed Stevens-Johnson syndrome and had started treatment with phenytoin three weeks before developing red cell aplasia. The patient presented with severe anaemia and bone marrow biopsy confirmed red cell aplasia. Phenytoin was discontinued and he was given a blood transfusion and treated with folic acid. He recovered fully. Clinical opinion was that the lamotrigine or phenytoin treatment was probably the cause of the aplasia. Thus, a causal association with chloramphenicol seems unlikely. The second serious case was a woman in her 60 s with cirrhosis of the liver; she developed pancytopenia 71 days after a single course of chloramphenicol eye drops. She was not admitted to hospital and reported no symptoms. The last serious case was a woman in her 80 s who had melaena seven days after a prescription for chloramphenicol eye drops. She was found to have pancytopenia and died from gastrointestinal bleeding 12 weeks later.

\section{Comment}

Even in the unlikely event that all three cases were caused by chloramphenicol eye drops, these data indicate that the risk of serious haematological toxicity after treatment with ocular chloramphenicol is in the order of 3 per 442543 patients or 3 per 674148 prescriptions.

The risk of serious haematological toxicity attributable to chloramphenicol eye drops is small. Chloramphenicol eye drops are cheap and effective. Their continued use for eye infections seems to be a safe clinical strategy.

Contributors: TL initiated the study hypothesis. TL, AMS, and $\mathrm{HJ}$ participated equally in the design, analysis, and writing of this report.

Funding: The Boston Collaborative Drug Surveillance Program is supported in part by grants from Astra Hässle, Bayer, Berlex Laboratories, Boots Healthcare International, Ciba-Geigy, GlaxoWellcome, Hoechst, RW Johnson Pharmaceutical Research Institute, Merck Research Laboratories, Organon, and Pfizer.

Conflict of interest: None.

1 Doona M, Walsh JB. Use of chloramphenicol as topical eye medication: time to cry halt? BMJ 1995;310:1217-1218.

2 Rayner SA, Buckley RJ. Ocular chloramphenicol and aplastic anaemia. Is there a link? Drug Safety 1996;14:273-276.

3 Jick HH, Jick SS, Derby LE. Validation of information recorded on general practitioner based computerised data resource in the United Kingdom. BMJ 1991;302:766-768.

4 Jick H, Myers MW, Dean AD. Sulfasalazine and mesalazine associated blood disorders. Pharmacotherapy 1995;15:176-181.

(Accepted 20 May 1997)

\section{Endpiece}

\section{Asherisms}

The difference between the maniac and the schizophrenic laugh is-mania and the world laughs with you, schizophrenia and you smile alone.

From A Sense of Asher, selected by Ruth Holland (BMA Publications, 1984)

\author{
Imperial Cancer \\ Research Fund \\ General Practice \\ Research Group, \\ University of \\ Oxford, Division of \\ Public Health and \\ Primary Care, \\ Institute of Health \\ Sciences, Oxford, \\ OX3 7LF \\ Tim Lancaster, \\ general practitioner \\ The Boston \\ Collaborative Drug \\ Surveillance \\ Program, Boston \\ University Medical \\ Center, Lexington, \\ MA 02173, USA \\ Hershel Jick, \\ associate professor of \\ medicine \\ Ann-Marie Swart, \\ epidemiologist \\ Correspondence to: \\ Dr Lancaster \\ Tim.Lancaster@ \\ dphpc.ox.ac.uk
}

BMJ 1998;316:667 